This document is the accepted manuscript version of the following article:

wigger, H., \& Nowack, B. (2019). Material-specific properties applied to an environmental risk assessment of engineered nanomaterials - implications on grouping and read-across concepts. Nanotoxicology, 13(5), 623-643.

https://doi .org/10.1080/17435390.2019.1568604

Material-specific properties applied to an environmental risk assessment of engineered nanomaterials - implications on grouping and read-across concepts

Henning Wigger ${ }^{\mathrm{a} *}$ and Bernd Nowack ${ }^{\mathrm{a}}$

${ }^{a}$ Empa, Swiss Federal Laboratories for Materials Science and Technology, Technology and Society Laboratory, Lerchenfeldstrasse 5, 9014 St. Gallen, Switzerland

*Corresponding author contact details: henning.wigger@googlemail.com

Wigger, H.; Nowack, B. (2019) Grouping by material-specific properties applied to a combined environmental exposure and hazard assessment of engineered nanomaterials. Nanotoxicology 13: 623-643.

https://doi.org/10.1080/17435390.2019.1568604 


\section{Material-specific properties applied to an environmental risk assessment of engineered nanomaterials - implications on grouping and read across concepts}

Engineered nanomaterials (ENMs) are intentionally designed in different nano-forms of the same parent material in order to meet application requirements. Different grouping and read-across concepts are proposed to streamline risk assessments by pooling nanoforms in one category. Environmental grouping concepts still are in their infancy and mainly focus on grouping by hazard categories. Complete risk assessments require data on environmental release and exposure not only for ENM but also for their nano-forms. The key requirement is to identify and to distinguish the production volumes of the ENMs regarding nano-form-specifc applications. The aim of our work was to evaluate whether such a grouping is possible with the available data and which influence it has on the environmental risk assessment of ENMs. A functionality-driven approach was applied to match the material-specific property (i.e. crystal form/morphology) with the functions employed in the applications. We demonstrate that for nano- $\mathrm{TiO}_{2}$, carbon nanotubes (CNTs), and nano- $\mathrm{Al}_{2} \mathrm{O}_{3}$ the total production volume can be allocated to specific nanoforms based on their functionalities. The differentiated assessments result in a variation of the predicted environmental concentrations for anatase vs. rutile nano- $\mathrm{TiO}_{2}$, singlewall vs. multi-wall CNTs and $\alpha$ - vs. $\gamma$-nano- $\mathrm{Al}_{2} \mathrm{O}_{3}$ by a factor of 2 to 13 . Additionally, the nano-form-specific predicted no-effect concentrations for these ENMs were derived. The risk quotients for all nano-forms indicated no immediate risk in freshwaters. Our results suggest that grouping and read-across concepts should include both a nano-form release potential for estimating the environmental exposure and separately consider the nano-forms in environmental risk assessments.

Keywords: nano-form, risk assessment, grouping, read-across, predicted environmental concentration, predicted no-effect concentration

\section{Introduction}

Engineered nanomaterials (ENMs) are appreciated not only due to their unique or improved properties but also because of their multitude of potential material configurations that can be 
used in various applications (Warheit, 2018). In addition to their elemental identity, ENMs can differ by their size (distribution), crystal form, coatings, ligands, doping and other physicochemical characteristics. Applications use these specifically designed ENMs (i.e. physico-chemical parameters) in order to fulfill certain technical requirements (Gilbertson et al., 2015). Each of these configurations of a substance (i.e. ENM) are defined as a nano-form in the REACH regulation (ECHA, 2017). For an environmental risk assessment, each of these nano-forms would have to be tested, if a case-by-case assessment is followed (Falinski et al., 2018, Landvik et al., 2018). Hence, the variety of potentially used nano-forms would require high time and economical efforts to perform environmental risk assessments. Because predictive (hazard) assessments are still in the early developmental stage (Fadeel et al., 2018), grouping concepts have become a focal point in current discussions to facilitate the risk assessment of ENMs (Oomen et al., 2015). Although several definitions of the term "grouping" exist within different regulations (Mech et al., 2018), the main objective of grouping concepts is the clustering of either several ENMs based on similar physico-chemical properties or of several nano-forms of the same ENM. This is usually done by focusing on intrinsic and/or extrinsic ENM characteristics, by mode of action, by biopersistence or by other biologically relevant descriptors (Lynch et al., 2014, Godwin et al., 2015). Grouping concepts allow streamlining risk assessments by setting priorities for testing, guiding endpoint and method selection in experimental setups and most importantly enabling read-across approaches in hazard assessments to fill data gaps and enable waiving of experimental testing (Lamon et al., 2018).

Different grouping and read-across concepts were proposed by researchers and were recently reviewed by Lamon et al. (2018). The grouping concepts proposed so far mainly focus on occupational health and safety aspects with a focal point on hazard assessments (Oomen et al., 2015, Arts et al., 2016). Whilst, for occupational health and safety assessments several 
grouping frameworks have been proposed (Lamon et al., 2018), the environmental counterpart is still in development (Hund-Rinke et al., 2018).

Generally, environmental risk assessments require data and information on both hazard and exposure assessments in order to derive the predicted no-effect concentration (PNEC) and the predicted environmental concentration (PEC), respectively. The division of the PEC by the PNEC yields the risk characterization ratio (RCR). A result above one indicates a need for more detailed assessments, while a result below one indicates no immediate risk (ECHA, 2016).

Several researchers attempted to evaluate ecotoxicological data to identify relevant physico-chemical parameters that can be used for grouping categories. Two studies focused on different nano-forms and obtained separate species sensitivity distribution (SSD), one commonly accepted method to derive the PNEC, of different nano-forms. Garner et al. (2015) compared several SSDs by separating data by ENM type and different nano-forms. They concluded that size, formulation and coating can alter the toxicity and that the dissolution is a strong predictor for the ecotoxicity for some ENMs. Chen et al. (2018) investigated data for several ENMs with regard to particle size, shape, coating and exposure time and did not find a significant statistical difference due to limited data. Silver nanoparticles (AgNP) coated with polyvinyl-pyrrolidon and sodium citrate showed lower PNECs than uncoated AgNPs, which was also in accordance to Garner et al. (2015), likely due to the aggregation affinity of uncoated AgNPs.

In the context of the environmental release as well as the fate and behavior models, the most relevant model parameters are the production volume, the allocation to product categories and their magnitude of release (i.e. the strength of the source with regard to the specific product) at different stages of their life-cycle (Wigger et al., 2018, Holden et al., 2014). Even though environmental fate and behavior models can consider physicochemical characteristics of ENMs, they rely on the initial input volume (i.e. ENM fraction released into a certain environmental compartment) that is determined by (probabilistic) material flow analysis (MFA) 
(Nowack, 2017). The specific challenge in MFA is the lack of data on the use of nano-forms in applications. Hence, MFA models subsume all ENMs of the same composition as a generic ENM without considering specific characteristics (i.e. nano-forms). Only two studies analyzed different nano-forms so far: Gottschalk et al. (2015) provided material flow diagrams for both photocatalytic and photostable nano- $\mathrm{TiO}_{2}$ and Hendren et al. (2013) modeled the fate of silver nanoparticles (AgNPs) with four different surface modifications during wastewater treatment. Both studies have shown that the nano-form has a substantial influence on the environmental release as well as on the fate and behavior of ENMs. In order to enable a grouping concept for environmental risk assessments of ENMs, not only hazard characteristics but also environmental release and exposure aspects should be considered in future frameworks.

This article aims to contribute to the environmental risk assessment of ENMs by collecting and analyzing data on environmental release and on adverse ecotoxicological effects for different nano-forms. The main research question is to identify differing RCRs of the nanoforms of an ENM and assess if grouping concepts can be considered for nano-forms in the context of environmental release and exposure assessment. Ten ENMs were screened with view on the data availability and applicability of grouping strategies based on the crystal form/morphology property. Three out of ten ENMs $\left(\mathrm{TiO}_{2}, \mathrm{CNTs}\right.$, and $\left.\mathrm{Al}_{2} \mathrm{O}_{3}\right)$ were selected based on the availability of ecotoxicological data and the feasibility to generate PECs specific to each nano-form considered. For each of these materials an extensive data collection was performed in order to derive the nano-form specific PNECs and PECs. Finally, we were able to present specific RCRs for different nano-forms of the same ENM indicating that nano-form specific assessments are required for certain ENMs such as nano- $\mathrm{TiO}_{2}$. 


\section{Materials \& Methods}

\section{Materials considered and allocation of production volumes to respective product categories}

The identification of the nano-forms actually used in nano-enabled products in commerce is challenging due to reasons such as confidentiality and the multitude of possible product applications. So far, in almost all exposure models, ENM have been considered as one nanoform, which does not reflect the variety of nano-forms in products used. Here, we assumed that the ENM properties are key to the corresponding product applications in which a certain functionality is required. When comparing the functionality required in products with the ENM functionality enabled by the ENM property, specific product applications can be identified. Hence, it is for some ENMs possible to differentiate certain product applications regarding the nano-form applied. It has to be noted that this assumption is not universally applicable due to the multitude of modification options of ENMs that may not be key properties. For example, when (coated) ENMs are used as an additive in a product, the product functionality does not necessarily depend on the additive and a differentiation is not possible based on this functionality. However, we have screened all major ENMs whether the allocation of the production volume to specific product categories is feasible based on the criteria applicability of the functionality-driven approach and data availability focusing on the crystal form/morphology..

\section{Carbon nanotubes}

CNTs are available in several configurations with the basic forms single-wall (SWNT), doublewall, multiwall carbon nanotubes (MWNT). Particularly, SWNT and MWNT are the most often mentioned nano-forms of CNTs. In general, both nano-forms differ in their amount of carbon (wall) layers, which is related to the synthesis of these materials and is the reasoning for the differentiation applied. Generally, both nano-forms of CNT are characterized by their good 
electrical and mechanical (i.e. structure reinforcing) properties, in which SWNTs surpasses the electrical performance of MWNTs (Zhang et al., 2011). Regarding the allocation of SWNT and MWNT to separated product categories, it is not clear how many SWNTs are actually used in the products due to the substitutability with MWNTs and comparably higher cost. As a first estimate, we have assumed that SWNTs are integrated in electronical applications due to the higher electronical performance, whilst MWNTs are used in all other applications. The overall production volume of CNTs is the lowest of other ENMs investigated in this article.

\section{Nano-aluminum oxide}

Alumina has several crystallographic configurations of which $\alpha-\mathrm{Al}_{2} \mathrm{O}_{3}$ and $\gamma-\mathrm{Al}_{2} \mathrm{O}_{3}$ are the main crystal forms (Kubiak et al., 2015, Trueba and Trasatti, 2005). The nano-sized form of $\mathrm{Al}_{2} \mathrm{O}_{3}$ shows improved physical, thermal, surface catalytic and electrical conductivity (Sahu et al., 2014). In the view of applications, nano- $\alpha-\mathrm{Al}_{2} \mathrm{O}_{3}$ has a higher hardness compared to nano- $\gamma$ $\mathrm{Al}_{2} \mathrm{O}_{3}$. Consequently, we have assumed that nano- $\alpha-\mathrm{Al}_{2} \mathrm{O}_{3}$ is used in abrasives or cutting applications in which a certain hardness is required (i.e. functionality). In contrast, nano- $\gamma$ $\mathrm{Al}_{2} \mathrm{O}_{3}$ is characterized by porous structures and is used in catalyst substrate, because of its lower thermal conductivity compared to nano- $\alpha-\mathrm{Al}_{2} \mathrm{O}_{3}$, for instance.

\section{Nano-titanium dioxide}

Nano- $\mathrm{TiO}_{2}$ has several crystallographic configurations of which anatase and rutile are the most relevant forms used in applications. (Nano-) $\mathrm{TiO}_{2}$ is normally a mixture of anatase and rutile (Shi et al., 2013). Rutile is considered as an inert form - although it also is slightly photocatalytically active -, whereas anatase is an active form of $\mathrm{TiO}_{2}$ with a higher refractive index, lower scattering and stronger absorption of ultraviolet (UV) radiation compared to rutile (Wang and Fan, 2014). Anatase has a wider absorption gap as well as a higher mobility of charge carriers compared to rutile, which likely leads to a higher surface reactivity and a better 
photocatalytic effect (Luttrell et al., 2014, De Matteis et al., 2016). A mix of both rutile and anatase (marketed as Degussa/Evonik P25 or EU reference material NM-105) has a higher photocatalytic reactivity than the pure crystal forms due to synergetic effects (Luttrell et al., 2014). Here, the photocatalytic activity was used as the functionality to allocate the crystal form to specific product categories (photocatalytic vs. photostable), which can be obtained in the supporting information (cf. Table S1). Accordingly, the ecotoxicological dataset was separated into rutile, P25 and anatase based on the crystalline fraction of anatase. If the anatase fraction was smaller than $50 \%$, the data points were attributed to the rutile dataset. If share of anatase was in the range of $65-90 \%$, the corresponding dataset was classified with P25. The anatase category included all those studies that have investigated nano- $\mathrm{TiO}_{2}$ with higher than $90 \%$ share of anatase. Regarding the allocation of the generic production volume, we assumed that rutile is primarily used in application in which the photostability is required (e.g. in sunscreens), whilst anatase employs its main property in photocatalytic applications.

\section{Probabilistic material flow modeling as a basis for estimating the predicted environmental concentrations}

In order to estimate the PECs of ENMs in several compartments, their environmental release from products throughout their life cycles has to be determined. The probabilistic material flow analysis (PMFA) is one common standard for this purpose, which was developed by Gottschalk et al. (2009) and has been used to derive materials flows for a range of ENMs (CaballeroGuzman et al., 2015, Gottschalk et al., 2015, Sun et al., 2014, Wang et al., 2016, Adam and Nowack, 2017, Wigger et al., 2018). Recently, PMFA has been extended by considering dynamic aspects (Wang and Nowack, 2018a, Sun et al., 2016, Sun et al., 2017, Giese et al., 2018, Bornhöft et al., 2016). The static MFA approach links several processes with transfer coefficients and balances all inputs and outputs over the period considered. Hence, the static MFA assumes a steady-state equilibrium. The probabilistic part of the MFA assigns to each 
parameter a probability distribution to the modal value and deploys a Monte-Carlo routine (100'000 samples) to quantify the uncertainty. By doing so, the results of the PMFA also show the uncertainty originating from the parameters, which is one major advantage compared to the deterministic MFA approaches. Here, we utilized a static PMFA due to the data constraints because time dependent production volumes, release amounts, and fate information in technical systems for specific nano-forms are not available.

The calculation of the nano-form specific material flows was based on data on the production volumes, product categories and transfer coefficients that were used in Sun et al. (2014), Gottschalk et al. (2015) as well as Wang and Nowack (2018a) for nano- $\mathrm{TiO}_{2}$, MWNTs/SWNTs and nano- $\mathrm{Al}_{2} \mathrm{O}_{3}$, respectively. As to the estimation of the production volume for nano- $\mathrm{Al}_{2} \mathrm{O}_{3}$, we used the reference year 2014 of the dynamic assessment that was performed by Wang and Nowack (2018a), whilst the calculations for nano- $\mathrm{TiO}_{2}, \mathrm{MWNTs} / \mathrm{SWNTs}$ are based on the reference year 2012.

In order to calculate the PEC values, the volumes of the environmental compartments have to be defined. We followed the REACH regulation (ECHA, 2016) as it was also applied by others (Sun et al., 2014, Wigger et al., 2018). This approach assumes that environmental compartments (i.e. air, soil divided into direct released and sludge treated, surface water) are homogenously mixed. The resulting PECs consequently are average concentrations for each compartment without considering any environmental transformations. Additionally, we have applied two regional scenarios for the area of Northern Europe (NE) and South-Eastern Europe (SEE) as done by Wang and Nowack (2018a). These regions were selected because they substantially differ in the volumes of ENMs produced, connection to WWTPs and waste management system (WMS) practices, as well as in the volume of the environmental compartments.

We are aware that ENMs undergo several transformations such as dissolution, heteroand homo-agglomeration as well as (re-)suspension that may influence the PEC considerably. 
However, the chosen ENM TiO $2, C N T$ and $\mathrm{Al}_{2} \mathrm{O}_{3}$ are considered to be quite stable and thus only agglomeration reactions would significantly affect their fate. Hence, we considered two worst-case scenarios, one considering total sedimentation of ENMs released to surface water (yielding the sediment concentrations) and the other considering no sedimentation (yielding the surface water concentrations). These estimated PECs can be subsequently used as input values for environmental fate and behavior models that are more dedicated to calculate PECs based on environmental fate and behavior processes.. By doing so, these scenarios cover the extrema of these influential parameters.

\section{Ecotoxicological data collection and derivation of probabilistic species sensitivity distributions, predicted no-effect concentrations and risk characterization ratios}

We first collected ecotoxicological in vivo data for the selected nano-forms in the freshwater compartment. Only data on the endpoints reproduction, growth, mortality and relevant metabolic process such as photosynthetic activity were considered as it was also applied by Coll et al. (2016) and recommended by ECHA (2008). Regarding the data quality, we applied for nano- $\mathrm{TiO}_{2}$ the DANA 2.0 criteria catalog (Steinbach et al., 2017) and identified approximately 165 data points with an adequate quality. For the other ENMs considered, data were very limited so that data points were selected as long as the studies had characterized the ENM with regard to the crystal form/morphology. This dataset was used for the calculation of the PNECs for each nano-form considered.

The PNEC of a substance is the estimated concentration at which no adverse effect is expected. Basically, two main approaches currently are regulatory compliant. First, deterministic PNECs can be derived by dividing the ecotoxicological value for one (relevant) species by an assessment factor (AF) considering the uncertainty associated to the data. Second, the species sensitivity distribution (SSD) approach takes into account several species at once by using the lowest ecotoxicological value or geometric mean per species. A cumulative SSD 
curve is fitted to this dataset based on a predefined distribution such as log-normal, log-logistic or others, for instance (ECHA, 2008). The final PNEC value is derived from the SSD curve by extracting the hazardous concentration $\left(\mathrm{HC}_{5}\right)$ at which five percent of the biological community is threatened (i.e. 95\% of the species are protected) and an additional AF of 1-5 has to be applied depending on the dataset quality (ECHA, 2008).

If only one data point was available for a nano-form (i.e. for nano- $\alpha-\mathrm{Al}_{2} \mathrm{O}_{3}$ ), we applied an AF of 1000 to calculate directly the PNEC based on the REACH guideline R.10 (ECHA, 2008). For all other cases, we have applied the $\mathrm{PSSD}^{+}$approach that was recently advanced by Wigger et al. (in preparation), who took the work of Gottschalk and Nowack (2013) as a basis.The $\mathrm{PSSD}^{+}$computes the $\mathrm{HC}_{5}$ using probabilistic elements for all ecotoxicity data points of each species, and calculates 10'000 PSSDs based on a Monte-Carlo routine for this data set. Then, the $\mathrm{HC}_{5}$ is extracted out of each PSSD and the PNEC distribution is obtained. The advantage of the PSSD ${ }^{+}$approach is that it considers the complete dataset and represents it as it is without aggregating or omitting data points. Therefore, the $\mathrm{PSSD}^{+}$approach is applicable to small and large datasets by avoiding the fitting problem of conventional SSDs (Wigger et al., in preparation).

The PSSD+ approach takes chronic no observed effect concentrations (NOECs) as inputs, because these are preferred over acute values in the REACH context (ECHA, 2008). Therefore, we applied to each ecotoxicological value two AFs for converting them from acute to chronic values and also to harmonize the dose-descriptors by transforming them into a NOEC value. Generally, ecotoxicological values were given as ECx (effective concentration at which a response of ' $\mathrm{x}$ ' percent is observed, ICx (Inhibitory concentration at which an inhibition of ' $\mathrm{x}$ ' percent is observed regarding a specific biological function), LCx (lethal concentration that is expected to cause death to $\mathrm{x} \%$ of the population), LOEC (lowest observed effect concentration) or NOEC. The applied AFs are listed in Table SX and are either based on the REACH guideline R.10 (ECHA, 2008), if applicable, or we took the corresponding OECD test guidelines as an 
orientation for the AF values. It has to be noted that AFs generally are still in debate due to the fact that standard AFs cannot consider substance and species specificity, which underlines the need of incorporating probability distributions in such assessments.

In the PSSD ${ }^{+}$approach, for each of the species-specific values a probability distribution was derived by considering the range of NOECs reported and the coefficients of variation linked to the inter-laboratory variation ( $\pm 30 \%)$ and the assessment factors $( \pm 50 \%)$. The minima and maxima of each species-specific distribution were estimated by the error propagation as described in Kawecki et al. (2018) combining these individual uncertainties into a total uncertainty range. If one data point per species was available, a triangular distribution was built, with the NOEC value as the mode and the minimum and maximum values determined by error propagation. If two data points were at hand, a trapezoidal distribution was generated by considering the modes of the data points, the minimum of the lowest NOEC and maximum of the highest NOEC values at the edges. When more than two data points per species were available, a distribution was derived combining uniform distributions in between all mode values and assessing the edges in a similar way for the other cases.

From these species-specific distributions, 10'000 PSSDs were calculated by applying a Monte-Carlo routine. Finally, the probability distribution of the PNEC was estimated by extracting the $\mathrm{HC}_{5}$ of each PSSD calculated Due to the objective of this study, no additional AF was applied (i.e. AF of one), which might be necessary in regulatory context depending on the data quality.

The RCR was obtained by dividing the PEC distributions by the PNEC distributions for each nano-form. A RCR above one shows a potential risk, which should be further investigated, whereas a RCR below one shows no immediate reason for concern. 


\section{Results}

\section{Applicability of exposure and hazard assessment and selection of nano-forms}

Ten major ENMs were screened whether a grouping of specific nano-forms is applicable to environmental exposure and hazard assessment. The results are shown in Table 1. Whilst crystal form or morphology-specific hazard assessment is (theoretically) possible for all ENM-classes, the material flow modeling is restricted by the knowledge on the specific use of nano-forms in applications. In ecotoxicological studies, the materials were usually well described and the applicability was limited only due to data availability. Regarding the environmental exposure assessment, the ENMs $\mathrm{Ag}, \mathrm{Au}, \mathrm{CuO}, \mathrm{ZnO}, \mathrm{Ce}_{\mathrm{x}} \mathrm{O}_{\mathrm{y}}$ and iron oxides could not be related to a unique identifier based on their functionalities that are used in specific product categories. For example, nano-Ag, nano- $\mathrm{Au}$, nano $\mathrm{CuO}$ and nano-ZnO have antimicrobial properties (Beyth et al., 2015), which principally make them useable in the same application. Additionally, the ENMs can be coated or functionalized that would mask the core functionality of the ENM used in the application. Consequently, it was not feasible to allocate these ENMs to an application due to the interchangeability of different nano-forms of the same ENM-class in an application. Finally, three major ENMs CNTs, $\mathrm{Al}_{2} \mathrm{O}_{3}$, and $\mathrm{TiO}_{2}$ were selected to perform a group specific environmental risk assessment due to the availability of both hazard data and the potential to separate the flows into different form. Whilst nano- $\mathrm{TiO}_{2}$ had both a sound ecotoxicological dataset and separable product applications based on the functionality, CNTs and nano- $\mathrm{Al}_{2} \mathrm{O}_{3}$ were limited in terms of allocation of the production volume or availability of ecotoxicological data, respectively. 
Table 1. Evaluation of ENMs regarding the feasibility to differentiate exposure and hazard assessment for nano-forms.

\begin{tabular}{|c|c|c|c|c|c|}
\hline ENM & nano-form & property/functionality & \multicolumn{2}{|c|}{ differentiation possible for } & \multirow[t]{2}{*}{ remark } \\
\hline & & & PEC & PNEC & \\
\hline \multirow{2}{*}{$\mathrm{TiO}_{2}$} & anatase/P25 & photocatalytically active & O & O & \multirow{2}{*}{$\begin{array}{l}\text { The exposure assessment is possible with regard to the allocation of the production volume to nano-form specific product categories (score: } \\
\text { green). } \\
\begin{array}{l}\text { The hazard assessment would allow nano-form specific assessments, because the ENMs are characterized in the experimental studies. The data } \\
\text { availablity is generally good compared to other nanomaterials investigated. (score: green). }\end{array}\end{array}$} \\
\hline & rutile & photostable & O & O & \\
\hline \multirow{3}{*}{$\begin{array}{l}\mathrm{ZnO} / \mathrm{Ag} / \\
\mathrm{CuO} / \mathrm{Au}\end{array}$} & & \multirow{3}{*}{$\begin{array}{l}\text { e.g. antimicrobial, UV-blocking, } \\
\text { catalytically active, optical effects }\end{array}$} & & & \\
\hline & coated & & O & O & \multirow{2}{*}{ 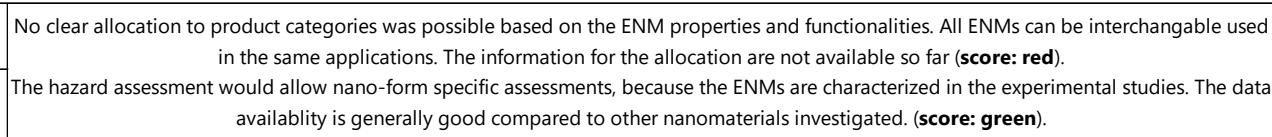 } \\
\hline & uncoated & & 0 & O & \\
\hline & & & & & \\
\hline \multirow{2}{*}{$\mathrm{Al}_{2} \mathrm{O}_{3}$} & alpha & hardness & O & (1) & \multirow{2}{*}{$\begin{array}{l}\text { The exposure assessment is possible with regard to the allocation of the production volume to nano-form specific product categories (score: } \\
\text { green). } \\
\begin{array}{l}\text { Nano-form specific PNECs can be principally derived, but the data availability on ecotoxicological studies is very limited. Therefore, the results } \\
\text { can be only interpreted as a preliminary result (score: yellow). }\end{array}\end{array}$} \\
\hline & gamma & higher thermally conductive than alpha- $\mathrm{Al}_{2} \mathrm{O}_{3}$ & O & O & \\
\hline & & & & & \\
\hline \multirow[t]{2}{*}{ CNT } & MWNT & & O & O & \multirow{2}{*}{ 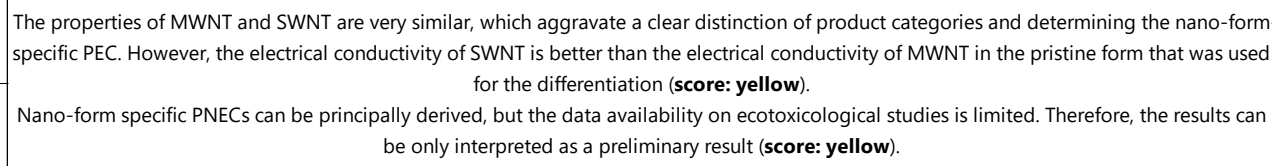 } \\
\hline & SWNT & higher electrical conductivity than MWNTs & O & 0 & \\
\hline \multirow{4}{*}{ Iron oxide } & & & & & \\
\hline & hematite & \multirow{3}{*}{$\begin{array}{l}\text { catalytically active, optical effects, } \\
\text { UV-blocking, thermally and electrically conductive, } \\
\text { anti-(ferromagnetic) }\end{array}$} & O & (1) & \multirow{3}{*}{$\begin{array}{l}\text { Although some applications can be identified and IONP forms associated to them, product categories cannot be differentiated based on the } \\
\text { crystal form (score: red). } \\
\text { Ecotoxicological data is rare for IONP-forms, but a differentiation of nano-form is principially possible (score: yellow) }\end{array}$} \\
\hline & maghemite & & 0 & P & \\
\hline & $\begin{array}{l}\text { magnetite } \\
\text { goethite }\end{array}$ & & ? & (1) & \\
\hline & & & & & \\
\hline \multirow{2}{*}{$\mathrm{Ce}_{x} \mathrm{O}_{x}$} & $\mathrm{Ce}_{2} \mathrm{O}_{3}(\mathrm{III})$ & \multirow{2}{*}{$\begin{array}{l}\text { e.g. catalytically active, } \\
\text { abrasive resistant }\end{array}$} & O & (1) & \multirow{2}{*}{$\begin{array}{l}\text { Ceria has several properties, which are not distinguishable based on the crystal form or oxidation state. Hence, the allocation to nano-form } \\
\text { specific product categories is not yet possible (score: red). } \\
\text { Ecotoxicological data is rare for the ceria nano-forms, but a differentiation of nano-form is principially possible (score: yellow) }\end{array}$} \\
\hline & $\mathrm{Ce}_{3} \mathrm{O}_{4}(\mathrm{IV})$ & & O & (1) & \\
\hline & & & & & \\
\hline \multirow{2}{*}{$\mathrm{SiO}_{2}$} & amorph & & O & (1) & \multirow{2}{*}{$\begin{array}{l}\text { The determination of nano-form specific environmental exposure assessment is possible since recent studies (Wigger et al 2018, Giese et al. } \\
\text { 2018) have published this data (score: green). } \\
\begin{array}{l}\text { Nano-form specific PNECs can be principally derived, but the data availability on ecotoxicological studies for the nano-forms of silica is } \\
\text { limited (score: yellow). }\end{array}\end{array}$} \\
\hline & crystalline & & O & (1) & \\
\hline
\end{tabular}


Legend: green = possible, yellow = partially possible, red = not possible; Abbreviations: PEC = predicted environmental concentration; PNEC = predicted no effect concentration; MWNT = multiwall carbon nanotubes; SWNT =single-wall carbon nanotubes; IONP = iron oxide nanoparticles 


\section{Estimated material flows and predicted environmental concentrations}

The results of the PMFA and the estimated PECs will be presented in the following subsections. The results are arranged by ENM and their nano-forms. The main results refer to the European system boundary, whereas results for the regions of NE and SEE are included in the supporting information (SI). The values described in the sections refer to the mean values.

\section{Nano- $\mathrm{TiO}_{2}$ - anatase and rutile}

The total production volume of nano- $\mathrm{TiO}_{2}$ has a mean of 10 '250 metric tons (Sun et al., 2014). The allocation of the production volume to the product categories was based on the photocatalytic activity or stability of nano- $\mathrm{TiO}_{2}$ (anatase) or nano- $\mathrm{TiO}_{2}$ (rutile), respectively. The allocation of the applications to the corresponding nano-form is shown in table S1. Following the applied allocation scheme, anatase nano- $\mathrm{TiO}_{2}$ represented 2'750 metric tons (27\%) and rutile nano- $\mathrm{TiO}_{2}$ 7'500 metric tons $(73 \%)$ of the total production volume. With this separation among applications, two separate material flow diagrams for both forms of nano- $\mathrm{TiO}_{2}$ could be constructed (cf. Figure 1). The main application of rutile was assumed in cosmetics (59\%) as a down-the-drain product that was released to wastewater during use. This resulted in 5’500 metric tons of rutile going through wastewater. Compared to anatase with 5 metric tons, rutile has a high direct

release of 370 metric tons to surface waters mainly due to the use in sunscreens. Most of the wastewater fraction is treated in the wastewater treatment plant (WWTP). Because of the high WWTP removal efficiency, the majority of rutile ended up in the sewage sludge that is subsequently used as fertilizer to some extent. Thus, the most relevant sinks for rutile were the compartments sludge treated soil (1'600 metric tons), surface water (2'100 metric tons) as well as landfill (2'200 metric tons) as it is depicted in Figure 1. In contrast 
to rutile, the main applications of anatase were paints with a share of $8 \%$, electronics with $7 \%$ and filters with $6 \%$. These product categories mainly comprised applications with ENMs embedded in a matrix. Consequently, their environmental releases during usage were low and the compartments receiving most of the flows from PMC were landfill (960 metric tons) and recycling/WMS for further treatment (650 metric tons). 

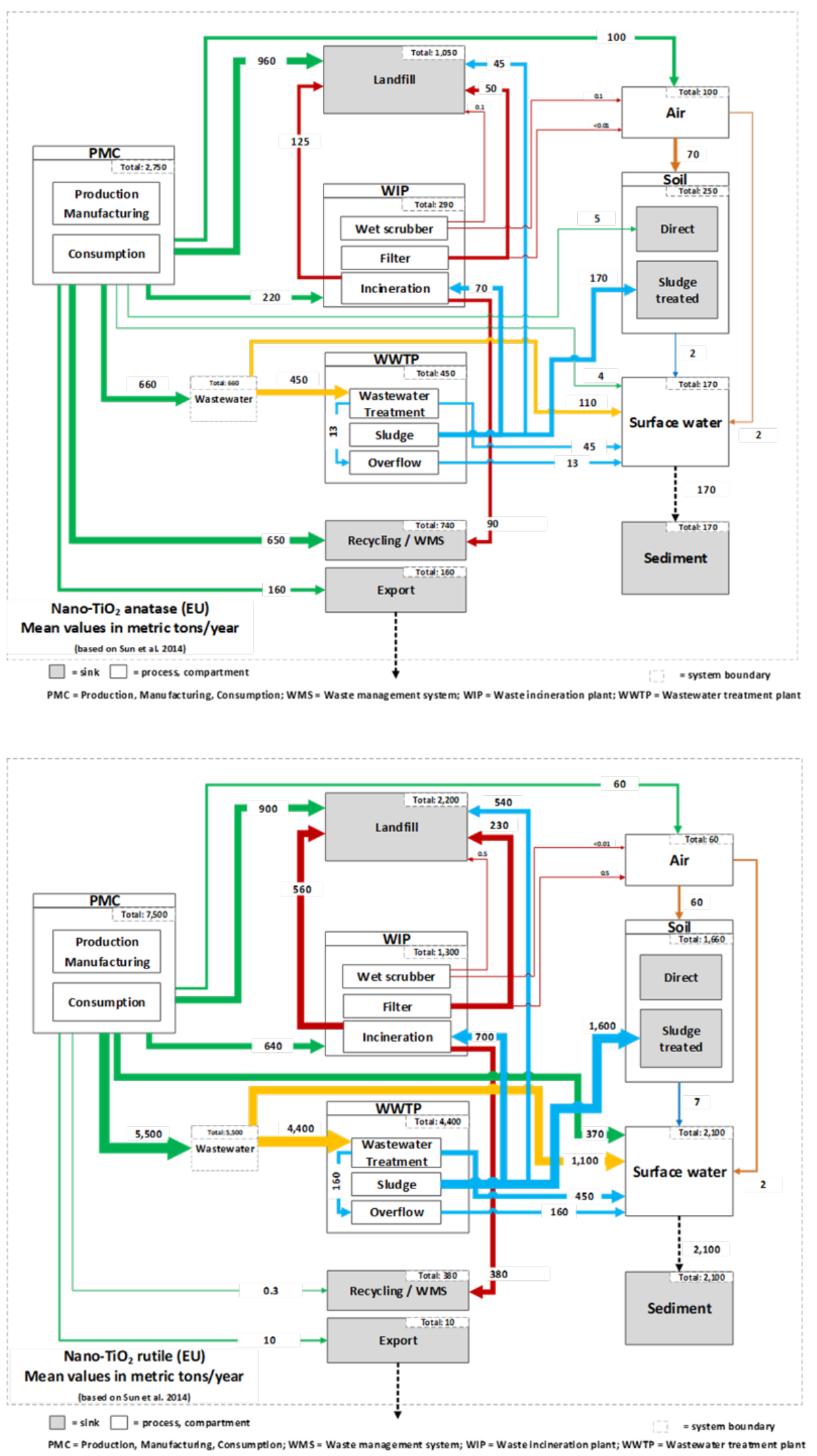

Figure 1. Material flow charts for nano- $\mathrm{TiO}_{2}$ (anatase) (top) and nano- $\mathrm{TiO}_{2}$ (rutile) (bottom) for Europe in 2012. 
$\mathrm{Nano}-\alpha-\mathrm{Al}_{2} \mathrm{O}_{3}$ and nano- $\gamma-\mathrm{Al}_{2} \mathrm{O}_{3}$

Nano- $\mathrm{Al}_{2} \mathrm{O}_{3}$ has an overall production volume of 14'800 metric tons (Wang and Nowack, 2018a). Nano- $\alpha-\mathrm{Al}_{2} \mathrm{O}_{3}$ is known for its hardness and consequently it is mostly used in abrasive or abrasive-resistant applications. Thus, nano- $\alpha-\mathrm{Al}_{2} \mathrm{O}_{3}$ constituted 12 '300 out of 14 '800 metric tons, whereas the remaining amount (i.e. $16 \%$ ) was allocated to nano- $\gamma$ $\mathrm{Al}_{2} \mathrm{O}_{3}$ (cf. table $\mathrm{S} 2$ for the allocation of product categories to the nano-form). The main applications of nano- $\alpha-\mathrm{Al}_{2} \mathrm{O}_{3}$ were cement (18\%), paints (16\%), automotive coatings (10\%) and cleaning agents (10\%). The material flow charts of Figure 2 depict the results. Cement, paints and automotive coatings usually go through well-organized recycling/WMSs in industrialized countries, which is why the main material flows were directed towards this technical compartment (61\%). Wastewater was another relevant release pathway (25\%), which was influenced by the cleaning agent application. In the recycling/WMS, most of ENMs go through sorting of embedding materials and transfer to either landfills or WIPs. Nano- $\gamma-\mathrm{Al}_{2} \mathrm{O}_{3}$ has less relevant material flows compared to nano- $\alpha-\mathrm{Al}_{2} \mathrm{O}_{3}$ and is dominated by the application filter (15\%). Consequently, the major material flows are towards the landfill or recycling/WMS for further treatment. 

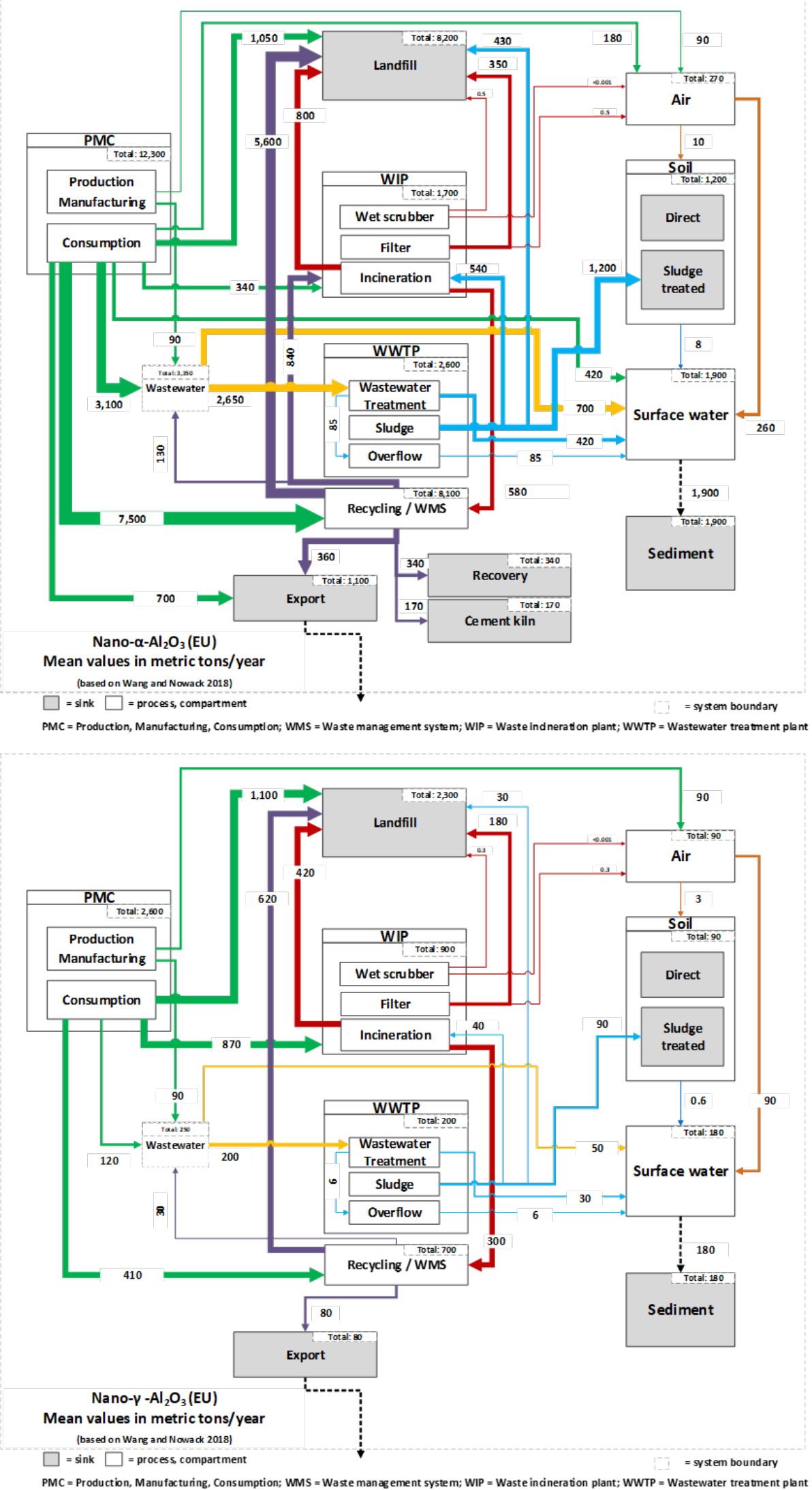

Figure 2. Material flow charts for nano- $\alpha-\mathrm{Al}_{2} \mathrm{O}_{3}$ (top) and nano- $\gamma-\mathrm{Al}_{2} \mathrm{O}_{3}$ (bottom) for Europe in 2014. 


\section{MWNT and SWNT}

CNTs had the lowest annual production volume with approximately 400 metric tons (mean) (Sun et al., 2014). The total production volume of CNTs was allocated to MWNT and SWNT with 97\% (equals 380 metric tons) and 3\% (15 metric tons), respectively (see table S3). Plastics (84\%), energy (9\%) and aerospace (6\%) were the main applications of MWNTs, whose use does not trigger high environmental release during use. Consequently, the majority of MWNTs was transferred to landfills with 230 metric tons (cf. Figure 3). The second relevant receiving compartment was WIP with 90 metric tons and the recycling/WMS with 40 metric tons originating from the production, manufacturing and consumption box (PMC). The main application of SWNTs were electronics, leading to material flows from the PMC to the recycling/WMS compartment (8.3 metric tons) as well as to export (2 metric tons). It has to be noted that a major part of the disposed MWNTs and SWNTs are eliminated during the thermal treatment in the WIP. Thus, environmental releases of MWNTs and SWNTs from WIP were low compared to other ENMs. 

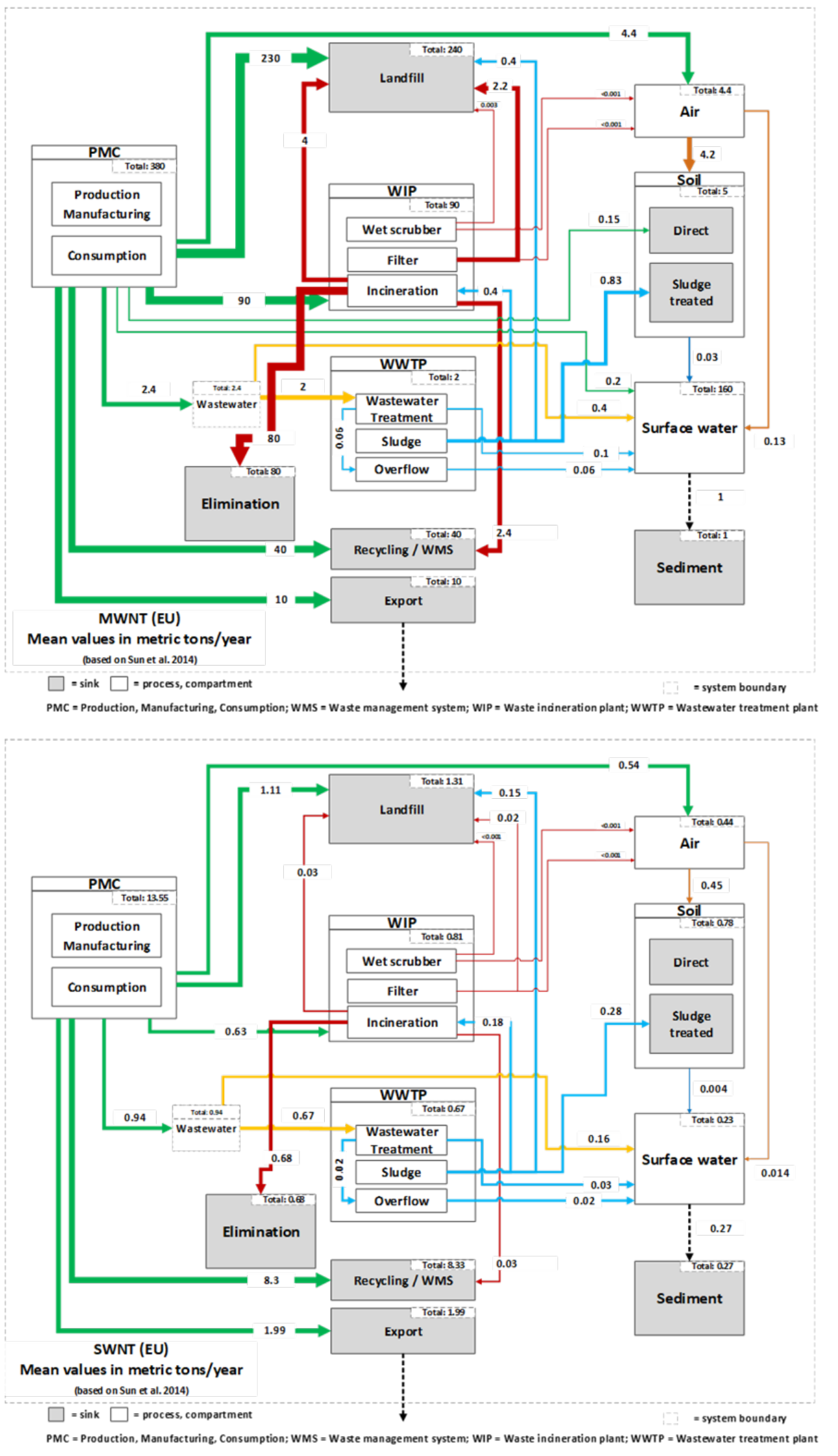

Figure 3. Material flow charts of MWNT (Top) and SWNT (bottom) for Europe in 2012. 
Determination of specific release profiles of the nano-forms per ENM considered In order to describe the characteristic environmental release profile of the two nano-forms of the same ENM, the released amounts of the nano-forms can be compared for the respective environmental compartment. A ratio was obtained by dividing the released amount of rutile and anatase, of MWNT and SWNT as well as $\alpha-\mathrm{Al}_{2} \mathrm{O}_{3}$ and $\gamma-\mathrm{Al}_{2} \mathrm{O}_{3}$. The higher the ratio, the more different were the applications of the nano-forms regarding the environmental release. These release profiles are depicted in Figure 4 and are based on the material flows shown in Figures 1 to 3 . The ratios of nano- $\mathrm{TiO}_{2}$ rutile and anatase showed that the released amounts of rutile were in average 10 to 11 times higher than the release amounts of anatase into the environmental compartment. Exceptionally, anatase had a higher environmental release to the natural and urban soil compartment than rutile, which is shown in Figure 4 as a negative ratio. A similar pattern was obtained for $\alpha$ $\mathrm{Al}_{2} \mathrm{O}_{3} / \gamma-\mathrm{Al}_{2} \mathrm{O}_{3}$ in which the ratios for each compartment showed ratios in the range from 10 to 13 . The ratio of MWNT to SWNT was lower with 2.6 to 3.6 compared to those of the other ENMs considered. Interestingly, the main difference of MWNT/SWNT ratio of 9.8 was identified for the compartment natural and urban soil. This was related to the direct releases from paints in which MWNT were incorporated. Due to weathering processes, fractions can be consequently released to the soil (natural \& urban) compartment. 


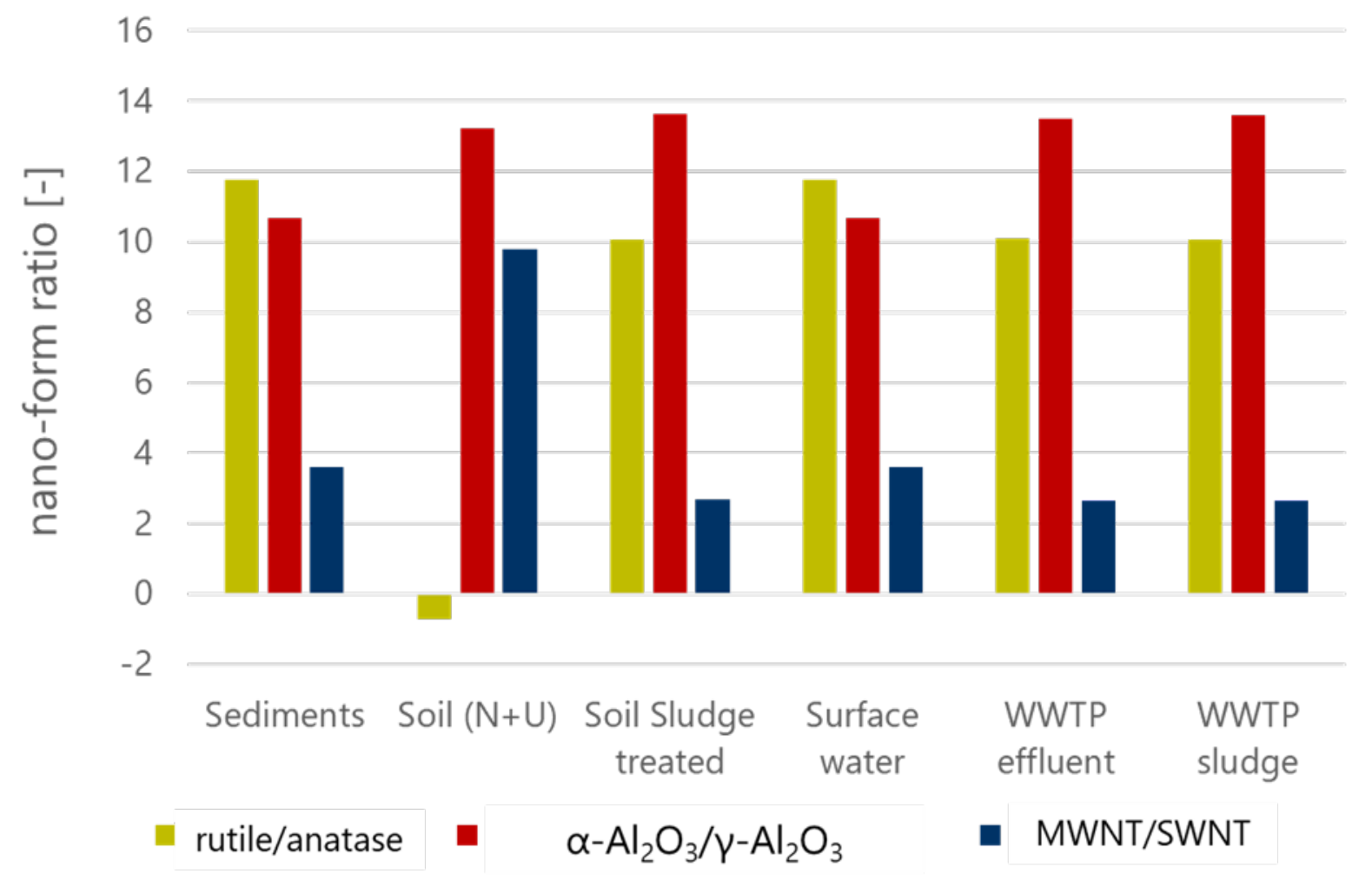

Figure 4. Environmental release profiles of of different nano-forms derived by the released amounts in each compartment. The higher the ratio, the larger is the difference of the released amounts of the nano-forms.

Legend: WWTP = wastewater treatment plant; $\mathrm{N}+\mathrm{U}=$ natural and urban

\section{Predicted environmental concentrations and regional variation}

The results for the European PECs are shown in Table 2, whereas the PECs for the regions NE and SEE are listed in the SI. Generally, the highest PEC values were calculated for nano- $\alpha-\mathrm{Al}_{2} \mathrm{O}_{3}$ and rutile nano- $\mathrm{TiO}_{2}$ due to the high production volume compared to the other nano-forms. The lowest PEC values were determined for MWNT and SWNT.

For the compartments surface water and sediments, the nano-forms showed the following ranking (based on the mean): nano- $\mathrm{TiO}_{2}$ rutile $>$ nano- $\alpha-\mathrm{Al}_{2} \mathrm{O}_{3}>$ nano- $\mathrm{TiO}_{2}$ anatase $>$ nano- $\gamma-\mathrm{Al}_{2} \mathrm{O}_{3}>$ MWNT $>$ SWNT, which was mainly determined by the production volume. The soil (natural + urban) compartment showed a different ranking with nano- $\alpha-\mathrm{Al}_{2} \mathrm{O}_{3}>$ nano- $\gamma-\mathrm{Al}_{2} \mathrm{O}_{3}>$ nano- $\mathrm{TiO}_{2}$ anatase $>$ nano- $\mathrm{TiO}_{2}$ rutile $>$ MWNT $>$ 
SWNT due to the consideration of direct releases. The compartment sludge treated soil ranked the nano-forms with nano- $\mathrm{TiO}_{2}$ rutile $>$ nano- $\alpha-\mathrm{Al}_{2} \mathrm{O}_{3}>$ nano- $-\mathrm{TiO}_{2}$ anatase $>$ nano- $\gamma-\mathrm{Al}_{2} \mathrm{O}_{3}>\mathrm{MWNT}>\mathrm{SWNT}$.

Table 2. Predicted environmental concentrations for the nano-forms considered for different European environmental and technical compartments*.

\begin{tabular}{|c|c|c|c|c|c|}
\hline \multicolumn{6}{|c|}{ nano- $\alpha-\mathrm{Al}_{2} \mathrm{O}_{3}$} \\
\hline & $\mathbf{Q}_{15}$ & Mode & Mean & $\mathbf{Q}_{85}$ & Unit \\
\hline Sediments & 1.3 & 1.7 & 1.9 & 2.4 & {$[\mathrm{mg} / \mathrm{kg}]$} \\
\hline Soil $(\mathrm{N}+\mathrm{U})$ & 1.1 & 1.4 & 1.6 & 2.1 & {$[\mu \mathrm{g} / \mathrm{kg}]$} \\
\hline Soil Sludge treated & $1 ' 090$ & $1 ' 450$ & 1'590 & 2'100 & {$[\mu \mathrm{g} / \mathrm{kg}]$} \\
\hline Surface water & 0.38 & 0.49 & 0.53 & 0.69 & {$[\mu \mathrm{g} / \mathrm{l}]$} \\
\hline WWTP effluent & 3.5 & 4.2 & 14 & 26.0 & {$[\mu \mathrm{g} / \mathrm{l}]$} \\
\hline WWTP sludge & 170 & 220 & 240 & 310 & {$[\mathrm{mg} / \mathrm{kg}]$} \\
\hline \multicolumn{6}{|c|}{ nano- $\gamma-\mathrm{Al}_{2} \mathrm{O}_{3}$} \\
\hline Sediments & 0.12 & 0.15 & 0.18 & 0.23 & {$[\mathrm{mg} / \mathrm{kg}]$} \\
\hline Soil $(\mathrm{N}+\mathrm{U})$ & 0.08 & 0.10 & 0.12 & 0.16 & {$[\mu \mathrm{g} / \mathrm{kg}]$} \\
\hline Soil Sludge treated & 80 & 100 & 120 & 160 & {$[\mu \mathrm{g} / \mathrm{kg}]$} \\
\hline Surface water & 0.03 & 0.04 & 0.05 & 0.07 & {$[\mu \mathrm{g} / \mathrm{l}]$} \\
\hline WWTP effluent & 0.25 & 0.28 & 1.1 & 1.9 & {$[\mu \mathrm{g} / \mathrm{l}]$} \\
\hline WWTP sludge & 12 & 15 & 18 & 24 & {$[\mathrm{mg} / \mathrm{kg}]$} \\
\hline \multicolumn{6}{|c|}{ Multi-wall carbon nanotubes } \\
\hline Sediments & 0.0006 & 0.0008 & 0.0010 & 0.0013 & {$[\mathrm{mg} / \mathrm{kg}]$} \\
\hline Soil $(\mathrm{N}+\mathrm{U})$ & 0.004 & 0.005 & 0.006 & 0.008 & {$[\mu \mathrm{g} / \mathrm{kg}]$} \\
\hline Soil Sludge treated & 0.80 & 1.04 & 1.23 & 1.66 & {$[\mu \mathrm{g} / \mathrm{kg}]$} \\
\hline Surface water & 0.0002 & 0.0002 & 0.0003 & 0.0004 & {$[\mu \mathrm{g} / \mathrm{l}]$} \\
\hline WWTP effluent & 0.0024 & 0.0027 & 0.0051 & 0.0081 & {$[\mu \mathrm{g} / \mathrm{l}]$} \\
\hline WWTP sludge & 0.12 & 0.16 & 0.18 & 0.24 & {$[\mathrm{mg} / \mathrm{kg}]$} \\
\hline \multicolumn{6}{|c|}{ Single-wall carbon nanotubes } \\
\hline
\end{tabular}




\begin{tabular}{|c|c|c|c|c|c|}
\hline Sediments & 0.0001 & 0.0001 & 0.0003 & 0.0004 & {$[\mathrm{mg} / \mathrm{kg}]$} \\
\hline Soil $(\mathrm{N}+\mathrm{U})$ & 0.0003 & 0.0003 & 0.0006 & 0.0009 & {$[\mu \mathrm{g} / \mathrm{kg}]$} \\
\hline Soil Sludge treated & 0.20 & 0.24 & 0.46 & 0.74 & {$[\mu \mathrm{g} / \mathrm{kg}]$} \\
\hline Surface water & 0.0000 & 0.0000 & 0.0001 & 0.0001 & {$[\mu \mathrm{g} / \mathrm{l}]$} \\
\hline WWTP effluent & 0.0007 & 0.0007 & 0.0019 & 0.0033 & {$[\mu \mathrm{g} / \mathrm{l}]$} \\
\hline WWTP sludge & 0.0309 & 0.0352 & 0.0686 & 0.1092 & {$[\mathrm{mg} / \mathrm{kg}]$} \\
\hline \multicolumn{6}{|c|}{ nano- $\mathrm{TiO}_{2}$ anatase } \\
\hline Sediments & 0.13 & 0.17 & 0.28 & 0.45 & {$[\mathrm{mg} / \mathrm{kg}]$} \\
\hline Soil $(\mathrm{N}+\mathrm{U})$ & 0.06 & 0.09 & 0.10 & 0.14 & {$[\mu \mathrm{g} / \mathrm{kg}]$} \\
\hline Soil Sludge treated & 80 & 110 & 210 & 340 & {$[\mu \mathrm{g} / \mathrm{kg}]$} \\
\hline Surface water & 0.04 & 0.05 & 0.08 & 0.13 & {$[\mu \mathrm{g} / \mathrm{l}]$} \\
\hline WWTP effluent & 1.1 & 1.3 & 5 & 10 & {$[\mu \mathrm{g} / \mathrm{l}]$} \\
\hline WWTP sludge & 13 & 16 & 30 & 50 & {$[\mathrm{mg} / \mathrm{kg}]$} \\
\hline \multicolumn{6}{|c|}{ nano- $\mathrm{TiO}_{2}$ rutile } \\
\hline Sediments & 1.8 & 2.3 & 3.3 & 5.1 & {$[\mathrm{mg} / \mathrm{kg}]$} \\
\hline Soil $(\mathrm{N}+\mathrm{U})$ & 0.03 & 0.05 & 0.07 & 0.11 & {$[\mu \mathrm{g} / \mathrm{kg}]$} \\
\hline Soil Sludge treated & 904 & 1026 & 2096 & 3363 & {$[\mu \mathrm{g} / \mathrm{kg}]$} \\
\hline Surface water & 0.50 & 0.67 & 0.94 & 1.44 & {$[\mu \mathrm{g} / \mathrm{l}]$} \\
\hline WWTP effluent & 12 & 15 & 50 & 100 & {$[\mu \mathrm{g} / \mathrm{l}]$} \\
\hline WWTP sludge & 140 & 160 & 320 & 510 & {$[\mathrm{mg} / \mathrm{kg}]$} \\
\hline
\end{tabular}

*The results are rounded to two or three digits.

Legend: WWTP = wastewater treatment plant; $\mathrm{N}+\mathrm{U}=$ natural and urban

As production volumes and waste management vary in different geographical systems, PECs can differ depending on the system studied. Therefore, PECs in Northern Europe and South Eastern Europe were calculated. The results can be obtained in table S7 for each nano-form and region. These PECs will be discussed together with the RCR variation as both are linearly dependent. 
The results of the data collection of the ecotoxicological endpoint values are summarized in tables S4-S6. Table 3 shows the overview on the number of data points and species collected for each nano-form for the freshwater compartment. Overall, nano- $\mathrm{TiO}_{2}$ has the highest number of data points despite the fact that the strictest quality criteria were applied. The crystal forms P25 and anatase had comparable numbers of data points and species, whilst rutile comprised only one third of the data points compared to other nano$\mathrm{TiO}_{2}$ forms. MWNT had twice as much data points compared to SWNT, although the numbers of species are at a similar level which was higher than the critical amount of ten data points. The data points for nano- $\mathrm{Al}_{2} \mathrm{O}_{3}$ was based on the PSSD study of Wang and Nowack (2018b). Additional studies were not found in the time considered for nano$\mathrm{Al}_{2} \mathrm{O}_{3}$ (i.e. until October 2018). Several data points of Wang and Nowack (2018b) could not be used due to missing information on the crystal form. Although $\gamma-\mathrm{Al}_{2} \mathrm{O}_{3}$ did not have sufficient amount of data points to build a representative PSSD, preliminary PSSDs for $\gamma-\mathrm{Al}_{2} \mathrm{O}_{3}$ were built. The PNEC for nano- $\alpha-\mathrm{Al}_{2} \mathrm{O}_{3}$ was derived by using the $\mathrm{LC}_{50}$ distribution divided by an assessment factor of 1000 .

Table 3. Number of data points and species for nano-forms considered in the freshwater compartment.

\begin{tabular}{|c|c|c|}
\hline nano-form & number of data points & number of species \\
\hline$\alpha-\mathrm{Al}_{2} \mathrm{O}_{3}$ & 1 & 1 \\
\hline$\gamma-\mathrm{Al}_{2} \mathrm{O}_{3}$ & 7 & 4 \\
\hline $\mathrm{SWNT}$ & 12 & 10 \\
\hline $\mathrm{MWNT}$ & 51 & 11 \\
\hline $\mathrm{TiO}_{2}$ anatase & 70 & 14 \\
\hline $\mathrm{TiO}_{2}$ rutile & 25 & 8 \\
\hline $\mathrm{TiO}_{2} \mathrm{P} 25$ & 69 & 17 \\
\hline
\end{tabular}

In Figure 5 and Table 4 the PSSDs and the PNEC distributions for all nano-forms are shown. Regarding nano- $\mathrm{TiO}_{2}$, species showed highest sensitivity to P25, which in 
turn resulted in a low mean PNEC of $4.5 \mu \mathrm{g} / \mathrm{l}\left(\mathrm{Q}_{15}: 2.8\right.$ - $\left.\mathrm{Q}_{85}: 6.2 \mu \mathrm{g} / \mathrm{l}\right)$ compared to rutile with a mean PNEC of $33 \mu \mathrm{g} / \mathrm{l}\left(\mathrm{Q}_{15}: 22\right.$ - Q85: $\left.45 \mu \mathrm{g} / \mathrm{l}\right)$ and anatase with $38 \mu \mathrm{g} / \mathrm{l}\left(\mathrm{Q}_{15}: 12\right.$ - Q85: $68 \mu \mathrm{g} / \mathrm{l})$. The mean PNECs for CNTs were $120 \mu \mathrm{g} / \mathrm{l}\left(\mathrm{Q}_{15}: 59\right.$ - Q $\left.\mathrm{Q}_{85}: 188 \mu \mathrm{g} / \mathrm{l}\right)$ for MWNTs and $99 \mu \mathrm{g} / \mathrm{l}\left(\mathrm{Q}_{15}: 63\right.$ - Q Q $\left._{85}: 135 \mu \mathrm{g} / \mathrm{l}\right)$. for SWNTs, at a similar level as the generic PNEC for CNT derived by Coll et al. (2016) with $55.6 \mu \mathrm{g} / \mathrm{l}\left(95^{\text {th }}\right.$ CI: 39.9-78.0 $\mu \mathrm{g} / \mathrm{l})$. Nano- $\gamma-\mathrm{Al}_{2} \mathrm{O}_{3}$ presented a PNEC distribution with a mean of $957 \mu \mathrm{g} / \mathrm{l}\left(\mathrm{Q}_{15}: 570\right.$ Q85: 1'300 $\mu \mathrm{g} / \mathrm{l})$. In contrast, the PSSD method was not applicable the for the dataset of nano- $\alpha-\mathrm{Al}_{2} \mathrm{O}_{3}$, which is why an $\mathrm{AF}$ of 1000 was applied to the only available value. The PNEC mean value for nano- $\alpha-\mathrm{Al}_{2} \mathrm{O}_{3}$ of 9'300 $\mu \mathrm{g} / \mathrm{l}\left(\mathrm{Q}_{15}:\right.$ 6'$\left.^{\prime} 080-\mathrm{Q}_{85}: 12^{\prime} 500 \mu \mathrm{g} / \mathrm{l}\right)$ was comparable high due to the limited dataset. We took this number into consideration to show the proof of concept by separating the product application based on the functionality. Therefore, the results for nano- $\alpha-\mathrm{Al}_{2} \mathrm{O}_{3}$ should be rather considered as a proof of concept than a final result. 
Nano- $\mathrm{TiO}_{2}$ (anatase) in the freshwater compartment

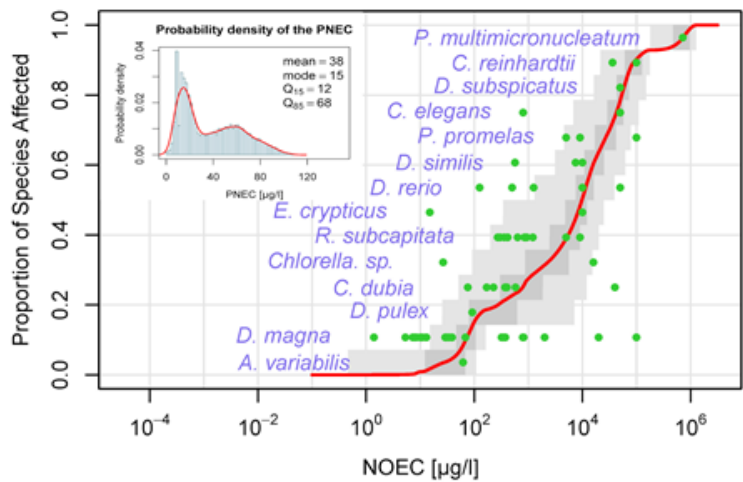

Nano- $\mathrm{TiO}_{2}$ (rutile) in the freshwater compartment

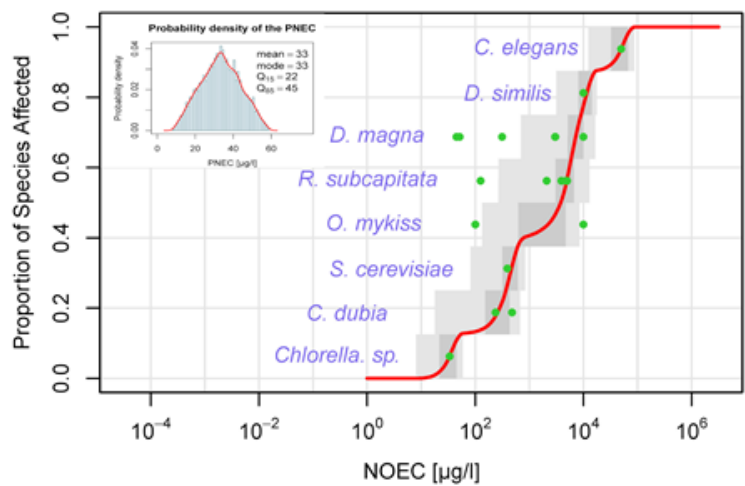

Nano-gamma- $\mathrm{Al}_{2} \mathrm{O}_{3}$ in the freshwater compartment

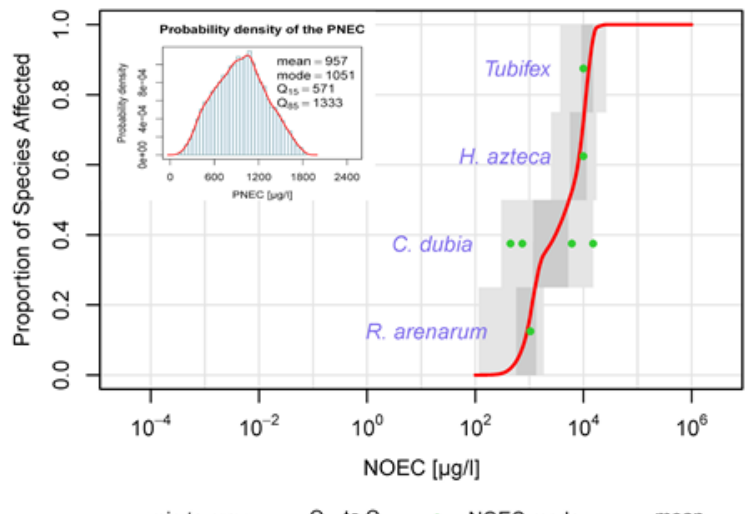

$\min$ to $\max -Q_{15}$ to $Q_{85}$ - NOEC mode - mean
Nano- $\mathrm{TiO}_{2}(\mathrm{P} 25)$ in the freshwater compartment

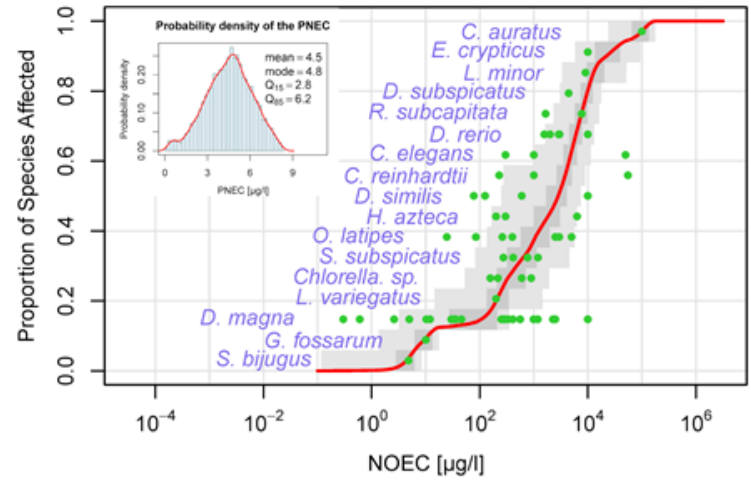

MWNTs in the freshwater compartment

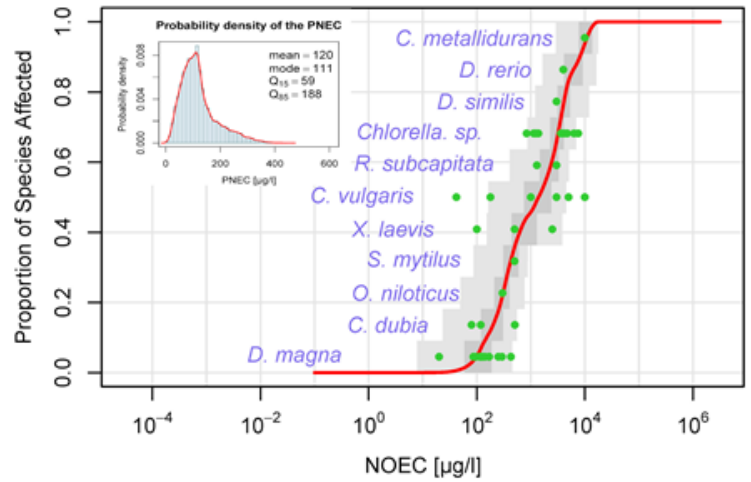

SWNTs in the freshwater compartment

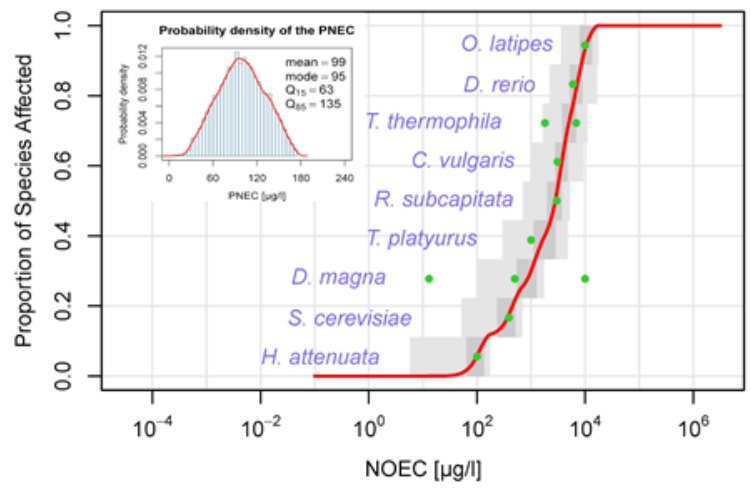

$\min$ to $\max -\mathrm{Q}_{15}$ to $\mathrm{Q}_{\mathrm{B} 5}$ - NOEC mode - mean

Figure 5. Derived probabilistic species sensitivity distributions and predicted no-effect concentrations (PNEC) for the nano-forms considered*. 
Table 4. Predicted no-effect concentrations for the different nano-forms derived from the probabilistic species sensitivity distributions*.

\begin{tabular}{|c|c|c|c|c|}
\hline Nano-form & mode $[\mu \mathrm{g} / \mathrm{l}]$ & mean $[\mu \mathrm{g} / \mathrm{l}]$ & 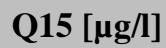 & 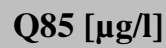 \\
\hline$* * \alpha-\mathrm{Al}_{2} \mathrm{O}_{3}$ & 9'340 & 9'300 & 6'080 & $12 ' 500$ \\
\hline$\gamma-\mathrm{Al}_{2} \mathrm{O}_{3}$ & 1'050 & 960 & 570 & 1'300 \\
\hline SWNT & 95 & 99 & 63 & 135 \\
\hline MWNT & 110 & 120 & 59 & 188 \\
\hline $\mathrm{TiO}_{2}$ anatase & 15 & 38 & 12 & 68 \\
\hline $\mathrm{TiO}_{2}$ rutile & 33 & 33 & 22 & 45 \\
\hline $\mathrm{TiO}_{2} \mathrm{P} 25$ & 4.8 & 4.5 & 2.8 & 6.2 \\
\hline
\end{tabular}

*The results are rounded to two or three digits.

** Please note that the values for nano- $\alpha-\mathrm{Al}_{2} \mathrm{O}_{3}$ are based on a single species PNEC

\section{European and regional risk characterization ratios}

The RCRs for each nano-form were obtained from the division of the PEC distributions by the PNEC distributions. The results are shown in Figure 6 and Table 5 . The ratio of PEC/PNEC determines the RCR and therefore high PECs and low PNECs may lead to RCRs similar to those obtained with low PEC and high PNEC values. The results for nano- $\mathrm{TiO}_{2}$ show that the RCRs obtained for rutile and P25 are similar, although different PECs and PNECs were derived for each of them. The maximal value of P25 can exceed the critical RCR value of one, but with a low likelihood. The RCR mean values for nano$\gamma-\mathrm{Al}_{2} \mathrm{O}_{3}$, nano- $\alpha-\mathrm{Al}_{2} \mathrm{O}_{3}$, MWNT and SWNT were several orders of magnitude lower than one. Whilst the crystal forms of nano- $\mathrm{Al}_{2} \mathrm{O}_{3}$ showed no differences in the RCR, MWNT and SWNT had different RCR mean values by a factor of three. 

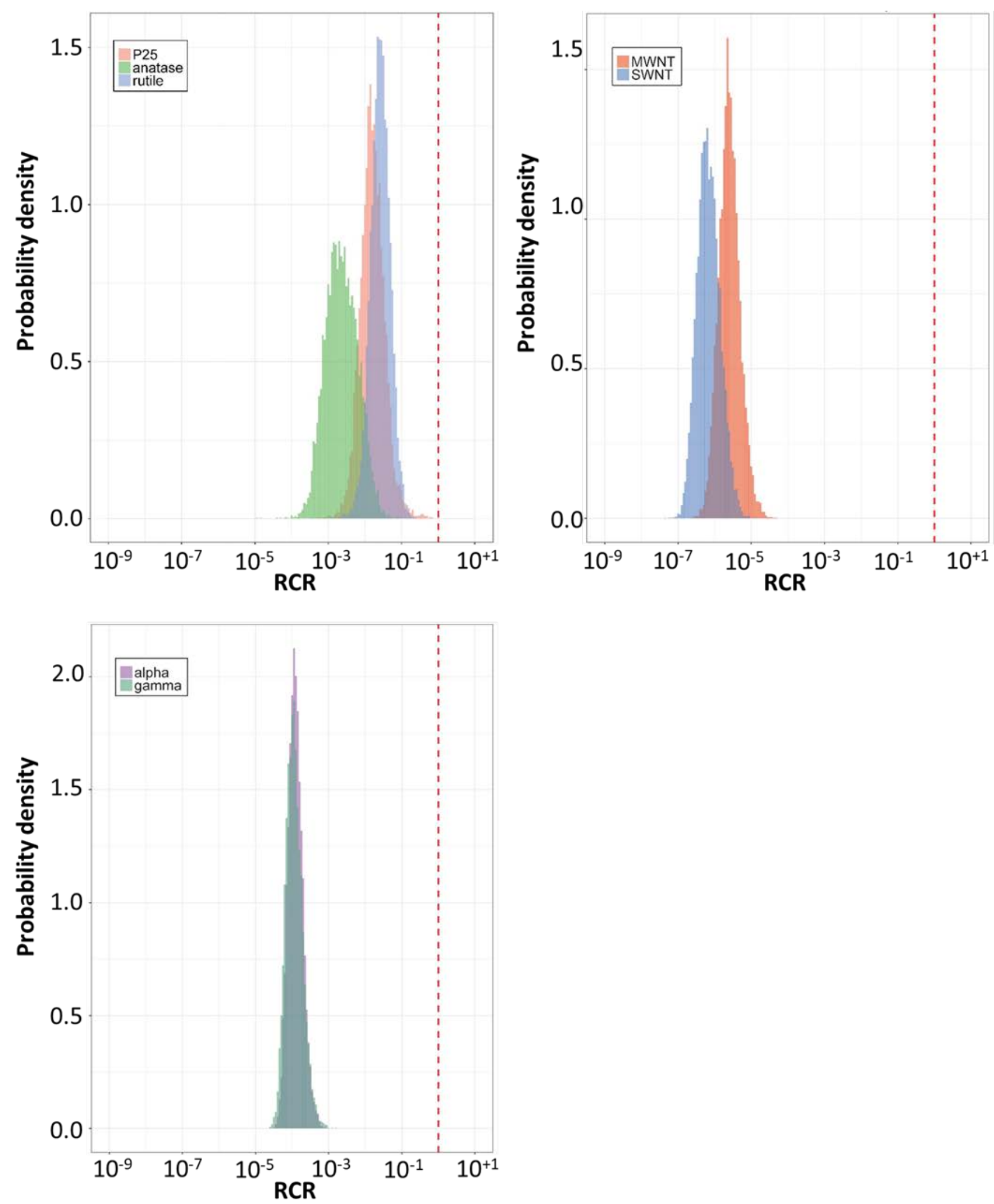

Figure 6. European risk characterization ratios (RCR) calculated for nano- $\mathrm{TiO}_{2}$ (top-left), CNTs (top-right) and nano- $\mathrm{Al}_{2} \mathrm{O}_{3}$ (bottom left). Please note that the values for nano- $\alpha$ - 
$\mathrm{Al}_{2} \mathrm{O}_{3}$ are based on a single species PNEC. The right handed side of dashed line (red) represents the area of potential risks.

Table 5. Risk characterization ratios for nano-form considered in Europe. Please note that the values for nano- $\alpha-\mathrm{Al}_{2} \mathrm{O}_{3}$ are based on a single species PNEC. The reddish color of the cells represents potential risks.

\begin{tabular}{|l|l|l|l|l|l|l|}
\hline Nano-form & Mode [-] & Mean [-] & $\mathbf{Q}_{15}[-]$ & Q85 [-] & Min[-] & Max[-] \\
\hline $\mathrm{TiO}_{2}$-anatase & $1.19 \mathrm{E}-03$ & $3.86 \mathrm{E}-03$ & $8.13 \mathrm{E}-04$ & $6.69 \mathrm{E}-03$ & $1.20 \mathrm{E}-05$ & $2.89 \mathrm{E}-01$ \\
\hline $\mathrm{TiO}_{2}$-P25 & $1.04 \mathrm{E}-02$ & $2.34 \mathrm{E}-02$ & $7.58 \mathrm{E}-03$ & $3.43 \mathrm{E}-02$ & $9.93 \mathrm{E}-05$ & $1.12 \mathrm{E}+00$ \\
\hline $\mathrm{TiO}_{2}$-rutile & $1.76 \mathrm{E}-02$ & $3.19 \mathrm{E}-02$ & $1.40 \mathrm{E}-02$ & $5.04 \mathrm{E}-02$ & $2.57 \mathrm{E}-04$ & $2.07 \mathrm{E}-01$ \\
\hline$\alpha-\mathrm{Al}_{2} \mathrm{O}_{3}$ & $9.81 \mathrm{E}-05$ & $1.38 \mathrm{E}-04$ & $7.82 \mathrm{E}-05$ & $1.98 \mathrm{E}-04$ & $2.68 \mathrm{E}-05$ & $8.97 \mathrm{E}-04$ \\
\hline$\gamma-\mathrm{Al}_{2} \mathrm{O}_{3}$ & $8.41 \mathrm{E}-05$ & $1.32 \mathrm{E}-04$ & $6.73 \mathrm{E}-05$ & $1.95 \mathrm{E}-04$ & $2.23 \mathrm{E}-05$ & $1.08 \mathrm{E}-03$ \\
\hline $\mathrm{MWNT}$ & $1.79 \mathrm{E}-06$ & $3.20 \mathrm{E}-06$ & $1.28 \mathrm{E}-06$ & $4.91 \mathrm{E}-06$ & $1.16 \mathrm{E}-07$ & $3.92 \mathrm{E}-05$ \\
\hline SWNT & $4.10 \mathrm{E}-07$ & $8.99 \mathrm{E}-07$ & $3.28 \mathrm{E}-07$ & $1.45 \mathrm{E}-06$ & $7.50 \mathrm{E}-08$ & $1.72 \mathrm{E}-05$ \\
\hline
\end{tabular}

The regionalized RCRs consider the geographical differences of NE and SEE. Table 6 summarizes the results for both regions. The calculated RCRs for the NE region showed no major variations compared to the European average region. In contrast, the RCRs for the SEE region indicated higher differences with a factor of 1 to 7.8 compared to the European average region. Particularly, the maximal RCR values for nano- $\mathrm{TiO}_{2} \mathrm{P} 25$ and anatase in the SEE scenario can exceed the critical value of one, although with a very low likelihood. However, the mean and mode RCR values for the nano-forms considered still were below one in the SEE scenario indicating no immediate risk, so far. Interestingly, the RCR value for nano- $\alpha-\mathrm{Al}_{2} \mathrm{O}_{3}$ decreased by $25 \%$ in the SEE scenario compared to European average region. Also, the regional results for MWNT and SWNT were higher (i.e. SEE scenario) or lower (i.e. NE scenarios), but do not exceed the critical RCR value of one. 
Table 6. Regional risk characterization ratios for Northern Europe and South Eastern Europe. The reddish box represents a potential risk. Please note that the values for nano$\alpha-\mathrm{Al}_{2} \mathrm{O}_{3}$ are based on a single species PNEC

\begin{tabular}{|c|c|c|c|c|c|c|}
\hline \multicolumn{7}{|c|}{ Northern European countries } \\
\hline Nano-form & Mode [-] & Mean [-] & $\mathbf{Q}_{15}[-]$ & $\mathbf{Q}_{85}[-]$ & Min[-] & Max[-] \\
\hline $\mathrm{TiO}_{2}$-anatase & $6.38 \mathrm{E}-05$ & $3.08 \mathrm{E}-04$ & 5.29E-05 & 5.39E-04 & $1.91 \mathrm{E}-06$ & $1.88 \mathrm{E}-02$ \\
\hline $\mathrm{TiO}_{2}-\mathrm{P} 25$ & $6.12 \mathrm{E}-04$ & $1.82 \mathrm{E}-03$ & 4.95E-04 & $2.81 \mathrm{E}-03$ & $7.85 \mathrm{E}-06$ & 1.35E-01 \\
\hline $\mathrm{TiO}_{2}$-rutile & $1.22 \mathrm{E}-03$ & $2.52 \mathrm{E}-03$ & $9.97 \mathrm{E}-04$ & $4.11 \mathrm{E}-03$ & $9.70 \mathrm{E}-07$ & $2.09 \mathrm{E}-02$ \\
\hline$\alpha-\mathrm{Al}_{2} \mathrm{O}_{3}$ & 7.43E-06 & $1.05 \mathrm{E}-05$ & 5.65E-06 & $1.53 \mathrm{E}-05$ & $1.86 \mathrm{E}-06$ & $6.61 \mathrm{E}-05$ \\
\hline$\gamma-\mathrm{Al}_{2} \mathrm{O}_{3}$ & $3.08 \mathrm{E}-06$ & 4.94E-06 & $2.48 \mathrm{E}-06$ & 7.37E-06 & $7.81 \mathrm{E}-07$ & $4.62 \mathrm{E}-05$ \\
\hline MWNT & $1.25 \mathrm{E}-07$ & $2.17 \mathrm{E}-07$ & $8.59 \mathrm{E}-08$ & $3.34 \mathrm{E}-07$ & 2.93E-09 & $3.40 \mathrm{E}-06$ \\
\hline SWNT & 2.37E-08 & 5.29E-08 & 1.92E-08 & 8.59E-08 & 2.76E-09 & $1.06 \mathrm{E}-06$ \\
\hline \multicolumn{7}{|c|}{ South Eastern European countries } \\
\hline Nano-form & Mode [-] & Mean [-] & $Q_{15}[-]$ & Q85 [-] & Min[-] & Max[-] \\
\hline $\mathrm{TiO}_{2}$-anatase & $1.04 \mathrm{E}-02$ & $2.99 \mathrm{E}-02$ & $6.78 \mathrm{E}-03$ & $5.29 \mathrm{E}-02$ & $8.55 \mathrm{E}-05$ & $1.63 \mathrm{E}+00$ \\
\hline $\mathrm{TiO}_{2}-\mathrm{P} 25$ & $8.74 \mathrm{E}-02$ & 1.83E-01 & $6.41 \mathrm{E}-02$ & $2.56 \mathrm{E}-01$ & $4.51 \mathrm{E}-04$ & $1.05 \mathrm{E}+01$ \\
\hline $\mathrm{TiO}_{2}$-rutile & $4.58 \mathrm{E}-02$ & 7.01E-02 & 3.34E-02 & 1.07E-01 & 8.95E-04 & $4.26 \mathrm{E}-01$ \\
\hline$\alpha-\mathrm{Al}_{2} \mathrm{O}_{3}$ & 6.87E-05 & $1.03 \mathrm{E}-04$ & 5.57E-05 & $1.49 \mathrm{E}-04$ & $1.61 \mathrm{E}-05$ & 5.39E-04 \\
\hline$\gamma-\mathrm{Al}_{2} \mathrm{O}_{3}$ & $8.71 \mathrm{E}-05$ & $1.39 \mathrm{E}-04$ & 7.23E-05 & 2.03E-04 & $2.65 \mathrm{E}-05$ & $1.74 \mathrm{E}-03$ \\
\hline MWNT & $4.49 \mathrm{E}-06$ & $8.04 \mathrm{E}-06$ & $3.25 \mathrm{E}-06$ & $1.24 \mathrm{E}-05$ & $6.81 \mathrm{E}-07$ & $8.90 \mathrm{E}-05$ \\
\hline SWNT & 1.13E-06 & $2.48 \mathrm{E}-06$ & $9.00 \mathrm{E}-07$ & 4.03E-06 & $1.36 \mathrm{E}-07$ & $5.01 \mathrm{E}-05$ \\
\hline
\end{tabular}

\section{Discussion}

The discussion will focus on three different questions that were addressed in the introduction. First, the influence of the product volume allocation on the PEC results will be examined. Second, the calculation of the PSSDs and PNECs will be discussed. Third, the implications of these results on grouping concepts will be highlighted. 


\section{Allocation of product volumes and predicted environmental concentrations}

In the present approach, the allocation of the production volume to product categories assumes that specific material properties (e.g. crystal form) are used to facilitate certain functionalities in applications. If the material property can be attributed to a functionality that is specifically required for an application, the production volume can be allocated to this product category. The proposed approach is applicable to the product categories that have a unique identifier with regard to the functionality of the nano-form. As many design strategies exist for modifying ENMs, also different ENMs can have similar functionalities (i.e. the nano-forms are interchangeable) depending on the surface modifications. Thus, the complete knowledge of the market and applications together with the applied nanoforms would be required to apply this functionality-driven approach to all ENMs. This knowledge is usually inaccessible from industries and authorities due to confidentiality and vague information reporting (Holden et al., 2014, Walser et al., 2017). However, this article has shown that for some ENMs the differentiation of nano-forms is feasible and relevant for the determination of the released amount, because the application defines the major environmental release pathway, e.g. mainly wastewater vs. mainly solid waste handling.

In order to perform a risk assessment, the released amounts need to be transformed into PEC values. The approach chosen in this work was to base this on the procedure outlines by the REACH guidance. The derived PECs are worst-case concentrations valid for a homogenously mixed compartment in the size of Europe. In order to understand the influence of regional variation, regions with very different wastewater treatment and waste management systems were considered in this study. The spatial variability can influence the PEC results by several orders of magnitude, which has also been shown by Gottschalk et al. (2011), Dale et al. (2015), and Meesters et al. (2016). Other authors 
reported similar differences for national waste management systems (Wigger et al., 2015, Wigger, 2017, Heggelund et al., 2016, Adam and Nowack, 2017). Furthermore, recently published models for ENM implement stocks and include temporal variations in the calculation of the environmental release (Bornhöft et al., 2016, Sun et al., 2016). These stocks shift environmental releases to later periods by considering the product lifespans. Depending on the product life span, PECs can be under- or overestimated compared to static models and particularly products with long lifespans can cause this delay (Muller et al., 2014). Typically, such products as for example paints and cements can have an expected service life of up to several decades. Recently, researchers have shown that considering product lifespans and release dynamics, the PEC values tend to increase over time because stocks become more relevant than the production volume per period entering the system (Song et al., 2017, Sun et al., 2017, Wang and Nowack, 2018a, Giese et al., 2018). The results of our study would likely differ compared to those obtained from dynamic models. The extent of the deviation depends on the number of applications included that have long product lifespans. Here, products (cements, paints) with a long lifespan were contained in nano- $\alpha-\mathrm{Al}_{2} \mathrm{O}_{3}$ with $40 \%$, nano- $\mathrm{TiO}_{2}$ (anatase) with $9 \%$ and MWNTs with $1 \%$ of their respective nano-form production volume. Consequently, the results of nano- $\alpha-\mathrm{Al}_{2} \mathrm{O}_{3}$ and nano- $\mathrm{TiO}_{2}$ (anatase) could differ accordingly. Nevertheless, the results of this article should be interpreted as first estimates and as a proof of concept regarding the allocation of production volumes to product categories. The main limiting factor to perform a dynamic assessment is knowledge about the changes of production and product use over time. As this is not available for specific nano-forms, we have decided to use for a first assessment a static MFA approach.

The PEC values that we provide do not include any environmental fate processes and are thus overestimating exposure. Nano- $\mathrm{TiO}_{2}, \mathrm{CNTs}$ and nano- $\mathrm{Al}_{2} \mathrm{O}_{3}$ can undergo 
homo- and predominantly heteroagglomeration processes that affect their environmental fate considerably (Lowry et al., 2012, Mitrano et al., 2015). The coupling of the environmental release flows calculated in our work with environmental fate models for ENMs (Garner et al., 2017, Meesters et al., 2014) would allow a more accurate prediction of PEC values. However, these improved PEC values would be smaller than the worstcase aquatic or sediments PECs derived in our work, which thus constitutes a precautionary assessment. A validation of the actual PECs in the real world is still difficult due to the challenges related to the environmental analytics (Nowack et al., 2015).

\section{Derivation of PSSDs and PNECs for the freshwater compartment}

The reliability of the results generally depends on the quality of the data set used. The recommended minimal number of species that are required for an SSD differs within regulations (Belanger et al., 2017). The Reach guidelines specify the requirements with at least ten species out of the eight taxonomic groups (ECHA, 2008) for applying the SSD approach. In contrast, Garner et al. (2015) proposed to have at least four species and Cedergreen et al. (2004) proposed six to eight species for generating a SSD (cf. Chen et al., 2018). None of the datasets in our study meets the REACH requirements (i.e. in terms of taxonomic groups) and would require a case-by-case evaluation as it is requested (ECHA, 2008). Here, the crystal forms of nano- $\mathrm{TiO}_{2}$ had the most comprehensive dataset. Thus, it was possible to apply strict selection criteria for nano- $\mathrm{TiO}_{2}$ to identify the reliable data points (approximately 165). In contrast, data for MWNT/SWNT were less frequently found so that all data points were used as long as the ENM was properly characterized regarding the morphology.

The PNEC values show considerable differences for the different nano-forms. Nano- $\mathrm{TiO}_{2} \mathrm{P} 25$ had the lowest PNEC mean value with $4.5 \mu \mathrm{g} / \mathrm{l}$ compared to anatase with 
$38 \mu \mathrm{g} / \mathrm{l}$ (mean) and rutile with $33 \mu \mathrm{g} / \mathrm{l}$ (mean). This result is reasonable, because P25 is known for being more efficient in photocatalytic applications than the pure crystal form of anatase (Luttrell et al., 2014), resulting in higher production of reactive oxygen species and subsequent toxicity. Surprisingly, the mean PNECs of rutile is at a similar level than the one of anatase, which contradicts the hypothesis that anatase is more photocatalytically active than rutile. Also, Hund-Rinke et al. (2018) found similar indications for anatase and rutile and identified comparable ranges of $\mathrm{EC}_{50}$ for both nanoforms (0.38-4.4 mg/l compared to $0.38-3.6 \mathrm{mg} / \mathrm{l}$, respectively). When analyzing the here used dataset of rutile and anatase in more detail, it shows that several data points of different species are at a similar low NOEC concentration of rutile, which explains the low PNEC of rutile compared to anatase due to the weight of these data points.. The reason can be found in the experimental conditions, as for instance, the most investigated species D. magna has NOEC values spanning several orders of magnitude, which is likely related to different intensities of illumination and constitution of the exposure media. However, if the derived PNEC values are compared to previously published values, the results are in the same range as it was determined for generic nano- $\mathrm{TiO}_{2}$ by Gottschalk et al. (2013) with $61.5 \mu \mathrm{g} / \mathrm{l}$ (median), Semenzin et al. (2015) with $20 \mu \mathrm{g} / \mathrm{l}$ (mean) and Coll et al. (2016) with $15.7 \mu \mathrm{g} / \mathrm{l}$ (mean). Also, the mean PNECs of MWNT and SWNT were at a similar level with mean values of $120 \mu \mathrm{g} / \mathrm{l}\left(\mathrm{Q}_{15}: 59\right.$ - $\left.\mathrm{Q}_{85}: 188 \mu \mathrm{g} / \mathrm{l}\right)$.and $99 \mu \mathrm{g} / \mathrm{l}\left(\mathrm{Q}_{15}\right.$ : 63 - Q85: $135 \mu \mathrm{g} / \mathrm{l})$, when the quantiles are considered, respectively. These results are in a similar range compared to Garner et al. (2015), who derived a generic PNEC of 3'500 $\mu \mathrm{g} / \mathrm{l}$ for CNTs based on $\mathrm{EC}_{50}$ values when an assessment factor of 10 is applied to convert the $\mathrm{EC}_{50}$ to a NOEC value. Nevertheless, the results of MWNT/SWNT in this study are higher compared to Coll et al. (2016), who derived an median PNEC of $55.6 \mu \mathrm{g} / \mathrm{l}$ for CNTs. This is related to the adapted PSSD approach used and the new data considered in 
this article. In contrast to the review of Jackson et al. (2013), who postulated differences in the ecotoxicological sensitivity of D. magna to both MWNT and SWNT, the PSSDs approach used in our work did not show a significant difference between the two forms. In order to facilitate such conclusions, comparable numbers of experimental data would be required. The PNECs for both forms of nano- $\mathrm{Al}_{2} \mathrm{O}_{3}$ were considerably larger by several orders of magnitude than the generic PNEC $(120 \mu \mathrm{g} / \mathrm{l})$ determined by Wang and Nowack (2018b). The reason is that about half of the data set used by Wang and Nowack (2018b) was not usable due to missing specification on the crystal form of $\mathrm{Al}_{2} \mathrm{O}_{3}$. The PNEC for $\alpha-\mathrm{Al}_{2} \mathrm{O}_{3}$ was not determined by the SSD-approach but by using the assessment factors defined in the REACH guidance (ECHA, 2008). Hence, the derived PNEC should be interpreted more like an indication for a potential NOEC range and less as the final result. The research still is ongoing and with new upcoming data the shape and value of PNEC values can change. However, it has to be considered that a general trade-off between data quality and data quantity has to be made. In either way, few high-quality data points or more lower-quality data points would limit the representativeness of the (P)SSD. Generally, nano- $\mathrm{Al}_{2} \mathrm{O}_{3}$ is expected to be toxic only in very high concentrations (Stanley et al., 2010).

\section{Risk characterization ratios and implications for grouping and read across concepts}

As the RCRs depend on both PEC and PNEC values, they underlie the same aforementioned limitations. Particularly, the regional PEC has shown to which extent it can vary depending on the regional variations of relevant model parameters (up to a factor of eight). These differences are mainly linked to the population (production volume used), population connected to WWTPs, and the volume of the local environmental compartment. However due to the predominating data limits, the RCR results have to be 
interpreted as a tendency of the nano-form towards the reason of concerns. Furthermore, the allocation of specific nano-forms to applications is crucial to consider in environmental risk assessments since major environmental release pathways are influenced considerably by the product lifecycle (i.e. wastewater vs. solid waste treatment). Even nano-forms showing higher PNECs (i.e. less toxic), such as nano- $\gamma$ $\mathrm{Al}_{2} \mathrm{O}_{3}(960 \mu \mathrm{g} / \mathrm{l})$, can present high RCRs if their PEC is high.

By considering the nano-form specific assessment, the RCR (together with the PEC and PNEC) can vary considerably by several orders of magnitude, which was shown in this study for nano- $\mathrm{TiO}_{2}$. These results imply that some ENMs (and their nano-forms) cannot be clustered in grouping (and read-across) concepts due to their specificity in terms of both release profile (i.e. amounts, form and compartment) and adverse effects. For example, photocatalytical nano- $\mathrm{TiO}_{2}$ (i.e. anatase and P25) and photostable nano$\mathrm{TiO}_{2}$ (rutile) showed considerable differences not only in the PEC but also in the PNEC estimation, which would be an obstacle for a general grouping concept. Consequently, a careful testing of grouping concepts could be required with regard to different ENMs and their nano-forms focusing on hazard and exposure aspects. Particularly, future grouping concepts should include the environmental release potential by considering the nano-form specific releases throughout the product life cycle (i.e. together with production volume and its allocation to product categories).

\section{Conclusions}

Grouping concepts have moved into the center of the current discussion in order to enable and to streamline environmental risk assessments of ENMs. Generally, these grouping concepts focus on hazard related aspects and categorize ENMs by relevant intrinsic properties (e.g. size, reactivity, crystal form) and only partially consider extrinsic properties (Arts et al., 2016, Lamon et al., 2018). As both hazard and exposure contribute 
to the environmental risk, this study investigated the applicability of a selected grouping category "crystal form" to a comprehensive environmental risk assessment. The environmental risk assessment has been performed in three steps by considering the crystal form of selected ENMs (i.e. $\mathrm{TiO}_{2}, \mathrm{Al}_{2} \mathrm{O}_{3}$ and $\mathrm{CNT}$ ). First, the production volume was allocated to product categories based on the crystal form and associated functionalities that are required in specific applications. Second, environmental release and PECs as well as PNECs were determined by means of probabilistic material flow modeling and species sensitivity distribution and in case of nano- $\alpha-\mathrm{Al}_{2} \mathrm{O}_{3}$ on a single PNEC for all nano-forms considered. Third, nano-form specific RCRs were derived based on the previous steps. Whilst, PSSDs can be easily generated for the nano-forms considered when enough data is available, the allocation of the production volume (the most influential parameter in environmental exposure models) to specific product categories is not always feasible based on the functionality that the crystal form comprises. However, the RCR results for nano- $\mathrm{TiO}_{2}$ (anatase, rutile), MWNT/SWNT and nano- $\mathrm{Al}_{2} \mathrm{O}_{3}$ (alpha and gamma) indicated considerable differences with a factor up to eight when nano-forms of the same ENM are compared. Finally, the results implied that some ENMs (and their nano-forms) cannot be clustered in grouping (and read-across) concepts due to their specificity in terms of bothenvironmental release profile (i.e. amounts, form and compartment) and adverse effects, which should be carefully considered in future grouping concepts, if a combined risk assessment is followed in these approaches.

\section{Acknowledgements}

This work was financed by caLIBRAte which has received funding from the European Union's Horizon 2020 Research and Innovation Programme under Grant Agreement 686239. The authors acknowledge Delphine Kawecki's and Véronique Adam's help in the development of the codes necessary for this model. 


\section{Disclosure statement}

The authors declare no conflict of interest.

\section{Supplemental online material.}

Supplementary information (SI) available

\section{References}

ADAM, V. \& NOWACK, B. 2017. European country-specific probabilistic assessment of nanomaterial flows towards landfilling, incineration and recycling. Environmental Science: Nano, 4, 1961-1973.

ARTS, J. H., IRFAN, M. A., KEENE, A. M., KREILING, R., LYON, D., MAIER, M., MICHEL, K., NEUBAUER, N., PETRY, T., SAUER, U. G., WARHEIT, D., WIENCH, K., WOHLLEBEN, W. \& LANDSIEDEL, R. 2016. Case studies putting the decision-making framework for the grouping and testing of nanomaterials (DF4nanoGrouping) into practice. Regul Toxicol Pharmacol, 76, 234-61.

BELANGER, S., BARRON, M., CRAIG, P., DYER, S., GALAY-BURGOS, M., HAMER, M., MARSHALL, S., POSTHUMA, L., RAIMONDO, S. \& WHITEHOUSE, P. 2017. Future needs and recommendations in the development of species sensitivity distributions: Estimating toxicity thresholds for aquatic ecological communities and assessing impacts of chemical exposures. Integr Environ Assess Manag, 13, 664-674.

BEYTH, N., HOURI-HADDAD, Y., DOMB, A., KHAN, W. \& HAZAN, R. 2015. Alternative antimicrobial approach: nano-antimicrobial materials. Evid Based Complement Alternat Med, 2015, 246012.

BORNHÖFT, N. A., SUN, T. Y., HILTY, L. M. \& NOWACK, B. 2016. A dynamic probabilistic material flow modeling method. Environmental Modelling \& Software, 76, 69-80.

CABALLERO-GUZMAN, A., SUN, T. \& NOWACK, B. 2015. Flows of engineered nanomaterials through the recycling process in Switzerland. Waste Manag, 36, 33-43.

CEDERGREEN, N., SPLIID, N. H. \& STREIBIG, J. C. 2004. Species-specific sensitivity of aquatic macrophytes towards two herbicides. Ecotoxicol Environ Saf, 58, 31423.

CHEN, G., PEIJNENBURG, W. J., XIAO, Y. \& VIJVER, M. G. 2018. Developing species sensitivity distributions for metallic nanomaterials considering the characteristics of nanomaterials, experimental conditions, and different types of endpoints. Food Chem Toxicol, 112, 563-570.

COLL, C., NOTTER, D., GOTTSCHALK, F., SUN, T., SOM, C. \& NOWACK, B. 2016. Probabilistic environmental risk assessment of five nanomaterials (nano-TiO2, nano-Ag, nano-ZnO, CNT, and fullerenes). Nanotoxicology, 10, 436-44.

DALE, A. L., CASMAN, E. A., LOWRY, G. V., LEAD, J. R., VIPARELLI, E. \& BAALOUSHA, M. 2015. Modeling nanomaterial environmental fate in aquatic systems. Environmental Science \& Technology, 49, 2587-2593. 
DE MATTEIS, V., CASCIONE, M., BRUNETTI, V., TOMA, C. C. \& RINALDI, R. 2016. Toxicity assessment of anatase and rutile titanium dioxide nanoparticles: The role of degradation in different $\mathrm{pH}$ conditions and light exposure. Toxicol In Vitro, 37, 201-210.

ECHA 2008. Guidance on information requirements and chemical safety assessment Chapter R.10 : Characterisation of dose [concentration]-response for environment. Helsinki, Finland: European Chemicals Agency (ECHA).

ECHA 2016. Guidance on information requirements and chemical safety assessment chapter R.16: Environmental exposure estimation. 3.0 ed. Helsinki, Finland: European Chemicals Agency (ECHA).

ECHA 2017. Appendix R.6-1: Recommendations for nanomaterials applicable to the Guidance on QSARs and Grouping of Chemicals. Helsinki, Finland: European Chemicals Agency.

FADEEL, B., FARCAL, L., HARDY, B., VAZQUEZ-CAMPOS, S., HRISTOZOV, D., MARCOMINI, A., LYNCH, I., VALSAMI-JONES, E., ALENIUS, H. \& SAVOLAINEN, K. 2018. Advanced tools for the safety assessment of nanomaterials. Nat Nanotechnol, 13, 537-543.

FALINSKI, M. M., PLATA, D. L., CHOPRA, S. S., THEIS, T. L., GILBERTSON, L. M. \& ZIMMERMAN, J. B. 2018. A framework for sustainable nanomaterial selection and design based on performance, hazard, and economic considerations. Nat Nanotechnol, 13, 708-714.

GARNER, K. L., SUH, S. \& KELLER, A. A. 2017. Assessing the risk of engineered nanomaterials in the environment: Development and application of the nanoFate model. Environmental Science \& Technology, 51, 5541-5551.

GARNER, K. L., SUH, S., LENIHAN, H. S. \& KELLER, A. A. 2015. Species sensitivity distributions for engineered nanomaterials. Environ Sci Technol, 49, 5753-9.

GIESE, B., KLAESSIG, F., PARK, B., KAEGI, R., STEINFELDT, M., WIGGER, H., VON GLEICH, A. \& GOTTSCHALK, F. 2018. Risks, Release and Concentrations of Engineered Nanomaterial in the Environment. Sci Rep, 8, 1565.

GILBERTSON, L. M., ZIMMERMAN, J. B., PLATA, D. L., HUTCHISON, J. E. \& ANASTAS, P. T. 2015. Designing nanomaterials to maximize performance and minimize undesirable implications guided by the Principles of Green Chemistry. Chem Soc Rev, 44, 5758-77.

GODWIN, H., NAMETH, C., AVERY, D., BERGESON, L. L., BERNARD, D., BERYT, E., BOYES, W., BROWN, S., CLIPPINGER, A. J., COHEN, Y., DOA, M., HENDREN, C. O., HOLDEN, P., HOUCK, K., KANE, A. B., KLAESSIG, F., KODAS, T., LANDSIEDEL, R., LYNCH, I., MALLOY, T., MILLER, M. B., MULLER, J., OBERDORSTER, G., PETERSEN, E. J., PLEUS, R. C., SAYRE, P., STONE, V., SULLIVAN, K. M., TENTSCHERT, J., WALLIS, P. \& NEL, A. E. 2015. Nanomaterial categorization for assessing risk potential to facilitate regulatory decision-making. ACS Nano, 9, 3409-17.

GOTTSCHALK, F., KOST, E. \& NOWACK, B. 2013. Engineered nanomaterials in water and soils: a risk quantification based on probabilistic exposure and effect modeling. Environ Toxicol Chem, 32, 1278-87.

GOTTSCHALK, F., LASSEN, C., KJOELHOLT, J., CHRISTENSEN, F. \& NOWACK, B. 2015. Modeling flows and concentrations of nine engineered nanomaterials in the danish environment. Int J Environ Res Public Health, 12, 5581-602.

GOTTSCHALK, F. \& NOWACK, B. 2013. A probabilistic method for species sensitivity distributions taking into account the inherent uncertainty and variability of effects to estimate environmental risk. Integr Environ Assess Manag, 9, 79-86. 
GOTTSCHALK, F., ORT, C., SCHOLZ, R. W. \& NOWACK, B. 2011. Engineered nanomaterials in rivers - Exposure scenarios for Switzerland at high spatial and temporal resolution. Environmental Pollution, 159, 3439-3445.

GOTTSCHALK, F., SONDERER, T., SCHOLZ, R. W. \& NOWACK, B. 2009. Modeled environmental concentrations of engineered nanomaterials ( $\mathrm{TiO}(2), \mathrm{ZnO}, \mathrm{Ag}$, CNT, Fullerenes) for different regions. Environmental Science \& Technology, 43, 9216-9222.

HEGGELUND, L., HANSEN, S. F., ASTRUP, T. F. \& BOLDRIN, A. 2016. Semiquantitative analysis of solid waste flows from nano-enabled consumer products in Europe, Denmark and the United Kingdom - Abundance, distribution and management. Waste Management, 56, 584-592.

HENDREN, C. O., BADIREDDY, A. R., CASMAN, E. \& WIESNER, M. R. 2013. Modeling nanomaterial fate in wastewater treatment: Monte Carlo simulation of silver nanoparticles (nano-Ag). Sci Total Environ, 449, 418-25.

HOLDEN, P. A., KLAESSIG, F., TURCO, R. F., PRIESTER, J. H., RICO, C. M., AVILA-ARIAS, H., MORTIMER, M., PACPACO, K. \& GARDEATORRESDEY, J. L. 2014. Evaluation of exposure concentrations used in assessing manufactured nanomaterial environmental hazards: are they relevant? Environ. Sci. Technol., 48, 10541-10551.

HUND-RINKE, K., SCHLICH, K., KÜHNEL, D., HELLACK, B., KAMINSKI, H. \& NICKEL, C. 2018. Grouping concept for metal and metal oxide nanomaterials with regard to their ecotoxicological effects on algae, daphnids and fish embryos. NanoImpact, 9, 52-60.

JACKSON, P., JACOBSON, N. R., BAUN, A., BIRKEDAL, R., KÜHNEL, D., JENSEN, K. A., VOGEL, U. \& WALLIN, H. 2013. Bioaccumulation and ecotoxicity of carbonnanotubes. Chemistry Central Journal, 7.

KAWECKI, D., SCHEEDER, P. R. W. \& NOWACK, B. 2018. Probabilistic Material Flow Analysis of Seven Commodity Plastics in Europe. Environ Sci Technol, 52, 9874-9888.

KUBIAK, K., SZELIGA, D., SIENIASWKI, J. \& ONYSZKO, A. 2015. The Unidirectional Crystallization of Metals and Alloys (Turbine Blades). In: NISHINGA, T. \& RUDOLPH, P. (eds.) Handbook of Crystal Growth. Amsterdam, Boston, Heidelberg, London, New York, Oxford, Paris, San Diego, San Francisco, Singapore, Sydney, Tokyo: Elsevier.

LAMON, L., ASCHBERGER, K., ASTURIOL, D., RICHARZ, A. \& WORTH, A. 2018. Grouping of nanomaterials to read-across hazard endpoints: a review. Nanotoxicology, 1-19.

LANDVIK, N. E., SKAUG, V., MOHR, B., VERBEEK, J. \& ZIENOLDDINY, S. 2018. Criteria for grouping of manufactured nanomaterials to facilitate hazard and risk assessment, a systematic review of expert opinions. Regul Toxicol Pharmacol, 95, 270-279.

LOWRY, G. V., GREGORY, K. B., APTE, S. C. \& LEAD, J. R. 2012. Transformations of nanomaterials in the environment. Environ Sci Technol, 46, 6893-9.

LUTTRELL, T., HALPEGAMAGE, S., TAO, J., KRAMER, A., SUTTER, E. \& BATZILL, M. 2014. Why is anatase a better photocatalyst than rutile?--Model studies on epitaxial TiO2 films. Sci Rep, 4, 4043.

LYNCH, I., WEISS, C. \& VALSAMI-JONES, E. 2014. A strategy for grouping of nanomaterials based on key physico-chemical descriptors as a basis for safer-bydesign NMs. Nano Today, 9, 266-270. 
MECH, A., RASMUSSEN, K., JANTUNEN, P., AICHER, L., ALESSANDRELLI, M., BERNAUER, U., BLEEKER, E. A. J., BOUILLARD, J., DI PROSPERO FANGHELLA, P., DRAISCI, R., DUSINSKA, M., ENCHEVA, G., FLAMENT, G., HAASE, A., HANDZHIYSKI, Y., HERZBERG, F., HUWYLER, J., JACOBSEN, N. R., JELIAZKOV, V., JELIAZKOVA, N., NYMARK, P., GRAFSTROM, R., OOMEN, A. G., POLCI, M. L., RIEBELING, C., SANDSTROM, J., SHIVACHEV, B., STATEVA, S., TANASESCU, S., TSEKOVSKA, R., WALLIN, H., WILKS, M. F., ZELLMER, S. \& APOSTOLOVA, M. D. 2018. Insights into possibilities for grouping and readacross for nanomaterials in EU chemicals legislation. Nanotoxicology, 1-23.

MEESTERS, J. A., KOELMANS, A. A., QUIK, J. T., HENDRIKS, A. J. \& VAN DE MEENT, D. 2014. Multimedia modeling of engineered nanoparticles with SimpleBox4nano: model definition and evaluation. Environmental Science \& Technology, 48, 5726-5736.

MEESTERS, J. A. J., QUIK, J. T. K., KOELMANS, A. A., HENDRIKS, A. J. \& VAN DE MEENT, D. 2016. Multimedia environmental fate and speciation of engineered nanoparticles: a probabilistic modeling approach. Environmental Science: Nano, 3, 715-727.

MITRANO, D. M., MOTELLIER, S., CLAVAGUERA, S. \& NOWACK, B. 2015. Review of nanomaterial aging and transformations through the life cycle of nanoenhanced products. Environ Int, 77, 132-47.

MULLER, E., HILTY, L. M., WIDMER, R., SCHLUEP, M. \& FAULSTICH, M. 2014. Modeling metal stocks and flows: a review of dynamic material flow analysis methods. Environ Sci Technol, 48, 2102-13.

NOWACK, B. 2017. Evaluation of environmental exposure models for engineered nanomaterials in a regulatory context. NanoImpact, 8, 38-47.

NOWACK, B., BAALOUSHA, M., BORNHÖFT, N., CHAUDHRY, Q., CORNELIS, G., COTTERILL, J., GONDIKAS, A., HASSELLÖV, M., LEAD, J., MITRANO, D. M., VON DER KAMMER, F. \& WONTNER-SMITH, T. 2015. Progress towards the validation of modeled environmental concentrations of engineered nanomaterials by analytical measurements. Environ. Sci.: Nano, 2, 421-428.

OOMEN, A. G., BLEEKER, E. A., BOS, P. M., VAN BROEKHUIZEN, F., GOTTARDO, S., GROENEWOLD, M., HRISTOZOV, D., HUND-RINKE, K., IRFAN, M. A., MARCOMINI, A., PEIJNENBURG, W. J., RASMUSSEN, K., JIMENEZ, A. S., SCOTT-FORDSMAND, J. J., VAN TONGEREN, M., WIENCH, K., WOHLLEBEN, W. \& LANDSIEDEL, R. 2015. Grouping and Read-Across Approaches for Risk Assessment of Nanomaterials. Int J Environ Res Public Health, 12, 13415-34.

SAHU, R. K., HIREMATH, S. S., MANIVANNAN, P. V. \& SINGAPERUMAL, M. 2014. An Innovative Approach for Generation of Aluminium Nanoparticles Using Micro Electrical Discharge Machining. Procedia Materials Science, 5, 12051213.

SEMENZIN, E., LANZELLOTTO, E., HRISTOZOV, D., CRITTO, A., ZABEO, A., GIUBILATO, E. \& MARCOMINI, A. 2015. Species sensitivity weighted distribution for ecological risk assessment of engineered nanomaterials: the nTiO2 case study. Environ Toxicol Chem, 34, 2644-59.

SHI, H., MAGAYE, R., CASTRANOVA, V. \& ZHAO, J. 2013. Titanium dioxide nanoparticles: a review of current toxicological data. Part Fibre Toxicol, 10, 15. 
SONG, R., QIN, Y., SUH, S. \& KELLER, A. A. 2017. Dynamic Model for the Stocks and Release Flows of Engineered Nanomaterials. Environmental Science \& Technology, 51, 12424-12433.

STANLEY, J. K., COLEMAN, J. G., WEISS, C. A., JR. \& STEEVENS, J. A. 2010. Sediment toxicity and bioaccumulation of nano and micron-sized aluminum oxide. Environ Toxicol Chem, 29, 422-9.

STEINBACH, C., BOHMER, N., KRUG, H. F., KÜHNEL, D., NAU, K., PAUL, F., REITHEL, S. \& MARQUARDT, C. 2017. DaNa 2.0 - verlässliche Informationen zur Sicherheit von marktüblichen Nanomaterialien. Chemie Ingenieur Technik, 89, 232-238.

SUN, T. Y., BORNHOFT, N. A., HUNGERBUHLER, K. \& NOWACK, B. 2016. Dynamic probabilistic modeling of environmental emissions of engineered nanomaterials. Environmental Science \& Technology, 50, 4701-4711.

SUN, T. Y., GOTTSCHALK, F., HUNGERBUHLER, K. \& NOWACK, B. 2014. Comprehensive probabilistic modelling of environmental emissions of engineered nanomaterials. Environmental Pollution, 185, 69-76.

SUN, T. Y., MITRANO, D. M., BORNHOFT, N. A., SCHERINGER, M., HUNGERBUHLER, K. \& NOWACK, B. 2017. Envisioning Nano Release Dynamics in a Changing World: Using Dynamic Probabilistic Modeling to Assess Future Environmental Emissions of Engineered Nanomaterials. Environmental Science \& Technology, 51, 2854-2863.

TRUEBA, M. \& TRASATTI, S. P. 2005. $\gamma$-Alumina as a Support for Catalysts: A Review of Fundamental Aspects. European Journal of Inorganic Chemistry, 2005, 33933403.

WALSER, T., BOURQUI, R. M. \& STUDER, C. 2017. Combination of life cycle assessment, risk assessment and human biomonitoring to improve regulatory decisions and policy making for chemicals. Environmental Impact Assessment Review, 65, 156-163.

WANG, J. \& FAN, Y. 2014. Lung injury induced by TiO2 nanoparticles depends on their structural features: size, shape, crystal phases, and surface coating. Int J Mol Sci, 15, 22258-78.

WANG, Y., KALININA, A., SUN, T. \& NOWACK, B. 2016. Probabilistic modeling of the flows and environmental risks of nano-silica. Science of the Total Environment, 545-546, 67-76.

WANG, Y. \& NOWACK, B. 2018a. Dynamic probabilistic material flow analysis of nano-SiO2, nano iron oxides, nano-CeO2, nano-Al2O3, and quantum dots in seven European regions. Environmental Pollution, 235, 589-601.

WANG, Y. \& NOWACK, B. 2018b. Environmental risk assessment of engineered nano$\mathrm{SiO} 2$, nano iron oxides, nano-CeO2, nano-Al2 O3 , and quantum dots. Environ Toxicol Chem, 37, 1387-1395.

WARHEIT, D. B. 2018. Hazard and risk assessment strategies for nanoparticle exposures: how far have we come in the past 10 years? F1000Res, 7, 376.

WIGGER, H. 2017. Environmental release of and exposure to iron oxide and silver nanoparticles - prospective estimations based on product application scenarios, Wiesbaden, Germany, Springer Vieweg.

WIGGER, H., HACKMANN, S., ZIMMERMANN, T., KOSER, J., THOMING, J. \& VON GLEICH, A. 2015. Influences of use activities and waste management on environmental releases of engineered nanomaterials. Science of the Total Environment, 535, 160-171. 
WIGGER, H., KAWECKI, D., NOWACK, B. \& ADAM, V. in preparation. Systematic consideration of parameter uncertainty and variability in probabilistic species sensitivity distributions.

WIGGER, H., WOHLLEBEN, W. \& NOWACK, B. 2018. Redefining environmental nanomaterial flows: consequences of the regulatory nanomaterial definition on the results of environmental exposure models. Environmental Science: Nano, 5, 1372-1385.

ZHANG, Q., HUANG, J. Q., ZHAO, M. Q., QIAN, W. Z. \& WEI, F. 2011. Carbon nanotube mass production: principles and processes. ChemSusChem, 4, 864-89. 